\title{
Inflammation in Parkinson's Disease: Causes and Consequences
}

\author{
Louise M. Collins, André Toulouse and Yvonne M. Nolan \\ Department of Anatomy and Neuroscience, University College Cork \\ Ireland
}

\section{Introduction}

Parkinson's disease (PD) is the second most common progressive neurodegenerative disorder after Alzheimer's disease (AD) with a prevalence of $0.5-1 \%$ among persons older than 65 years of age (Toulouse \& Sullivan, 2008). The incidence increases to $2.6 \%$ in persons aged 85 and older, and has a mean age of onset of 55 years. Statistics released in 1990 from a unique global study carried out by the World Health Organisation, suggest that there are approximately 4 million PD patients worldwide. However, despite intensive research, the aetiology of this neurodegenerative disease still remains unclear and despite substantial efforts, a cure remains elusive. This, coupled with the increasing aging demographics, makes the importance of research into PD imperative, and the development of novel drug treatments a primary aim, both for economic and humanitarian purposes. The disease is a chronic, progressive neurodegenerative motor disorder, resulting in the selective loss of dopaminergic (DA) neurons within the substantia nigra (SN) pars compacta (pc) of the midbrain. As the disease progresses there is gradual circuitry degeneration within the nigrostriatal pathway, producing motor, cognitive and psychiatric symptoms (Braak et al., 2003). Lewy bodies are classified as the focal pathological hallmark of PD and their presence is necessary for the post-mortem diagnosis of the disease. They are not unique to PD however and are also found in other diseases such as dementia with Lewy Bodies and diffuse Lewy Body disease (Braak et al., 2003). PD can be further characterised by the presence of an accumulation of activated microglia within the SNpc (McGeer et al., 1988).

PD exists in many forms and can be classified into both familial and idiopathic (also referred to as sporadic) forms, with epidemiological studies indicating approximately $5-10 \%$ of cases as being familial, and $90-95 \%$ as idiopathic (Tomiyama et al., 2008). Familial PD can be transmitted in an autosomal dominant (AD-PD) or recessive fashion (AR-PD). The study of genetic forms of PD has led to a better understanding of the underlying molecular mechanisms occurring during the disease progression. To date, six genes (SNCA, LRRK2, PRKN, DJ-1, PINK1 and ATP13A2) have been implicated in familial forms of PD (Bekris et al., 2010). In contrast to idiopathic PD, the genetic forms of this disease display a significantly younger age of onset and a shorter disease duration (Pankratz \& Foroud, 2007). Despite this, patients with the autosomal dominant form of the disease have similar clinical and pathological features to those with idiopathic PD. In idiopathic PD, environmental factors such as toxins, free radicals and inflammation have been considered the most likely 
candidates as causative agents. For example, pesticides can induce oxidative stress (an increased production of activated oxygen species such as superoxide anions and hydroxyl radicals) which leads to lipid peroxidation, DNA damage and mitochondrial dysfunction (Dick, 2006; Jenner, 2003). Moreover, there is evidence to suggest that the oxidative stress that occurs at a basal level in the SNpc is increased during PD (Jenner, 2003). The involvement of inflammation in the progression of PD has been well documented and is generally typified by an accumulation of activated microglia in damaged regions of the brain (Gao \& Hong, 2008; Long-Smith et al., 2009). Initial evidence stems from a post-mortem study over twenty years ago, which demonstrated the presence of activated microglia and T-lymphocytes in the SNpc of a PD patient (McGeer et al., 1988). Since then, an abundance of studies have supported a role for neuroinflammation and activated microglia in the pathology of PD (Banati et al., 1998; Hirsch \& Hunot, 2009; Imamura et al., 2003; McGeer \& McGeer, 2004; Orr et al., 2002). Activated microglia are predominantly found in the SNpc in the vicinity of degenerating DA neurons in post-mortem PD brains, but have also been detected in the hippocampus, transentorhinal cortex, cingulate cortex and temporal cortex, where neuronal loss is also prevalent (Banati et al., 1998; Imamura et al., 2003; McGeer et al., 1988; Sawada et al., 2006). The presence of activated microglia in rat brains lesioned with 6hydroxydopamine (6-OHDA), a neurotoxin used to model PD, has been reported by numerous groups (Akiyama \& McGeer, 1989; Crotty et al., 2008; Depino et al., 2003; He et al., 2001). Further evidence implicating inflammation in PD comes from studies that report an increase in the expression of the pro-inflammatory cytokines, interleukin (IL)-1 $\beta$, tumour necrosis factor- $\alpha$ (TNF- $\alpha$ ) and IL-6 in PD patients compared with healthy subjects (Boka et al., 1994; Dobbs et al., 1999; Mogi et al., 1994a; Mogi et al., 1994b). Enzymes associated with inflammation, such as inducible nitric oxide synthase (iNOS) and cyclooxygenase-2 (COX2), have also been identified post-mortem in PD brains (Hunot et al., 1996; Knott et al., 2000).

\section{Neuroinflammation in Parkinson's disease}

\subsection{Microglia}

Microglia are the resident immune-competent cells of the central nervous system (CNS). They monitor the brain for invading pathogens and immune insults and are capable of stimulating an adaptive immune response (Garden \& Moller, 2006). Pio del Rio-Hortega first ignited interest in microglia in the early $20^{\text {th }}$ century when he identified them as a separate glial entity (del Rio Hortega, 1932), providing a complete and comprehensive framework of their involvement in brain pathology (Raivich et al., 1999). There are currently two proposed subsets of microglia residing within the CNS. There are the "resting" microglia found ramified throughout the brain parenchyma and mostly a permanent population, and the perivascular microglia, which are periodically replaced by bonemarrow derived elements and are strategically located in the basal lamina of brain capillaries and the choroid plexus (Santambrogio et al., 2001). These two subsets differ in their expression of leucocyte common antigen, CD45, which is high (CD45 high) in perivascular and low (CD45 low ) in parenchymal microglia (Sedgwick et al., 1991). The production of microglia is complex. There is an initial production of microglia during development, a constant turnover of microglia during adulthood and throughout senescence, and an up-regulated production of microglia in response to pathological conditions. Furthermore, each of these stages is likely to be governed by diverse 
mechanisms. The origin of microglia remains contentious, but the majority of the neuroscience community support the premise that they are derived from mesodermal precursor cells of hematopoietic lineage (Barron, 1995; Cuadros \& Navascues, 1998) due to their expression of macrophage antigens, such as F4/80, Fc receptor (FcR) and macrophage1 antigen (MAC-1) (Carson et al., 1998). Mesodermal precursor cells infiltrate the brain during embryonic and early postnatal phases of development and have the potential to differentiate into macrophages, dendritic cells (DCs) and granulocytes (Santambrogio et al., 2001). Factors which govern and propel this invasion are not widely understood but are believed to involve cell surface bound molecules and components of the extracellular matrix (Cuadros \& Navascues, 1998). As with the origin of microglia, the mechanism of microglial renewal in situ remains controversial. This prolonged controversy to unequivocally differentiate activated endogenous microglia from those of infiltrating blood monocytes is due to a lack of distinguishable cell surface or enzymatic markers (Ransohoff \& Cardona, 2010). In addition, the prevailing technique of lethally irradiated chimeras to examine this appears to be fraught with confounding factors. Ajami et al., (2007) utilised chimeric animals obtained through parabiosis, which does not require experimental manipulation, and found that microglial homeostasis is maintained independently of bone-marrow derived precursors. They also reported that mature resident microglia are capable of focal selfrenewal and microgliosis in response to insult or injury (Ajami et al., 2007).

Within the healthy adult brain microglia reside as a ubiquitously distributed quiescent cell population, representing $10-20 \%$ of non-neuronal cells within the CNS parenchyma. They are functionally related to peripheral tissue macrophages and other cells of the monocyte lineage, but differ in their down-regulated expression of a number of cytoplasmic molecules (Perry, 1998). Historically referred to as "resting" microglia, which discriminates them morphologically from their active amoeboid form found during insult to the CNS, they are characterised by a small rod-shaped somata and numerous elongated, highly ramified processes. Through their protrusions, they are in direct contact with astrocytes, neuronal cell bodies and blood vessels, suggesting that they dynamically interact with a variety of neural elements (Nimmerjahn et al., 2005). As immune effector cells of the CNS, they are extremely receptive to subtle change in their microenvironment, rapidly undergoing morphological as well as functional transformations (Ladeby et al., 2005). Although research in recent years has greatly advanced our knowledge of activated microglia, little has been established concerning the function of the microglia residing in the unperturbed CNS. This is due in part to the exceedingly complex predicament many have faced while trying to culture "resting" microglia in vitro. The removal and dissociation of cells from CNS tissue, either by mechanical or proteolytic means inevitably leads to some level of activation (Garden \& Moller, 2006). Many have observed microglial cells in vitro exhibiting an amoeboid morphology in a non-pathogenic environment. Eder and co-workers exposed murine microglia to astrocyte-conditioned medium and noted a dramatic transformation in morphology from a "resting" ramified appearance to "active" amoeboid microglia. within a few hours of treatment. As well as this, they observed a down-regulation in macrophage surface molecules such as major-histocompatibility complex (MHC) class-II, and the adhesion molecules leucocyte function-associated antigen-1 (LFA-1) and intercellular adhesion molecule-1 (ICAM-1) (Eder et al., 1999). Well-established histological approaches have allowed "resting" microglia to be examined in situ, capturing them in a "freeze-frame picture" at the time of being placed in fixative but this approach also has limitations and 
thus may obscure potentially important dynamic processes (Davalos et al., 2005). Advances in multi-photon in vivo microscopy however, have shed some light on the function of "resting" microglia in situ. By examining the behaviours of eGFP-expressing parenchymal microglia in heterozygous $\mathrm{CX}_{3} \mathrm{CR} 1$-mice, it was revealed that microglial processes are incessantly palpating their microenvironment. The protrusions extend and retract rapidly and dynamically, reaching up to several micrometres in length over intervals of seconds to minutes (Davalos et al., 2005; Nimmerjahn et al., 2005). It was postulated that their high motility serves as a "housekeeping" function allowing them to effectively manage the brain milieu and to clear the parenchyma of accumulated metabolic products and deteriorated tissue components (Nimmerjahn et al., 2005). Indeed it has been estimated that they are capable of probing the entire volume of the brain every $4-5$ hours. The highly ramified form of microglia covers $30-40 \mu \mathrm{m}$ in diameter and though their processes are in close proximity, they are not in direct contact, suggesting that each cell occupies its own exclusive patrol territory (McGeer \& McGeer, 2007; Raivich et al., 1999). As such, they are now more appropriately termed "surveillant" microglia to properly describe their rapid and continuous monitoring of the surrounding vicinity (Ransohoff \& Cardona, 2010).

"Surveillant" ramified microglia respond to activating stimuli with a rapid morphological transformation into "active" amoeboid microglia (Nakajima \& Kohsaka, 2001). Activated microglia are found in the brain under almost all pathological conditions and are involved in tissue repair, amplification of inflammatory effects, neuronal degeneration and the phagocytosis of dead cells and cellular debris (Davalos et al., 2005). Microglia express a perplexing array of cell surface receptors such as complement receptor 3 and MHC class I and II, whose up-regulation is concomitant with activation of microglia (Nakajima \& Kohsaka, 2001). These receptors play a pivotal role in enabling microglia to detect subtle changes in their microenvironment, triggering them to extend their processes to the surrounding area of insult, and to engulf damaged cells via phagocytosis (Davalos et al., 2005). In addition, microglia are considered the main antigen presenting cell (APC) population within the CNS, as both in vivo and in vitro studies have demonstrated their capacity for antigen presentation in response to a variety of CNS pathological conditions (Graeber \& Streit, 2010). Activation of microglia and the consequent up-regulation of MHC class II, CD40 and ICAM-1 stimulate T cell proliferation and the production of IL-2, IFNY and IL-4. However, the ability of endogenous microglia to act as APCs has been brought into question, with many postulating that it may be the role of perivascular macrophages or invading DCs (Perry, 1998). Today, growing evidence suggests that DCs do in fact participate in the regulation of T-cell responses (Teo \& Wong, 2010). Microglia in common with other cells of the myeloid lineage also have the ability to secrete immunomodulatory molecules such as cytokines, chemokines, neurotrophins, reactive oxygen and nitrogen species, which communicate signals to surrounding cells to regulate the innate immune response (Garden \& Moller, 2006). Cytokines, such as ILs, IFNs and TNFa/ $\beta$ are lowmolecular weight proteins that are usually classified as pro- or anti-inflammatory, and microglia express receptors for these cytokines in an autocrine feedback loop that is critical for down-regulating inflammation and restoration of homeostasis. In the brain, it has been reported that cytokines function in growth promotion, inhibition and proliferation of astrocytes and oligodendrocytes (Hanisch, 2002), modulation of neurotransmitter release (Zalcman et al., 1994) long-term potentiation (Nolan et al., 2005) behavioural impairments such as memory impairment (Yirmiya et al., 2002) anhedonia (Konsman et al., 2002) and anxiety (Anisman \& Merali, 1999). 


\subsection{Activated microglia in Parkinson's disease}

The first evidence for a role of inflammation in PD came from McGeer and colleagues who observed activated microglia and T cells in the post-mortem SNpc of a PD patient (McGeer et al., 1988). We now know from a multitude of studies that microglial activation and consequent neuroinflammatory processes play a role in PD (Hirsch \& Hunot, 2009). Whereas mild activation of microglia has apparent beneficial effects, chronic microglial activation in response to neuronal damage, as is evident in PD, results in the death of otherwise viable cells. Activation of microglia either directly via a toxin, pathogen or endogenous protein or indirectly from dying neurons may be both long-lived and selfpropelling due to positive feedback from degenerating neurons even after the initial insult has ceased (Gao \& Hong, 2008). This repetitive cycle of neurotoxic activation of microglia in response to neuronal damage is referred to as reactive microgliosis (Block et al., 2007) and is a feature of several brain pathologies (Carson et al., 1998). DA neurons in the SNpc are particularly susceptible to microglial-mediated neurotoxicity due to the high densities of microglia present (Kim et al., 2000). Thus, microglial activation and hence neuroinflammation, may be propagated and potentially amplify the destruction of neurons in PD (Gao \& Hong, 2008). Substances which are produced by dying DA neurons and can activate microglia include a-synuclein-aggregates (Zhang et al., 2005), neuromelanin (Wilms et al., 2003), adenosine triphosphate (ATP) (Davalos et al., 2005) and matrix metalloproteinase-3 (MMP-3) (Kim et al., 2007; Kim et al., 2005).

Aggregated a-synuclein, the major constituent of Lewy bodies in PD, has been reported to be surrounded by activated microglia or inflammatory mediators (McGeer et al., 1988; Yamada et al., 1992). It has also been shown to activate microglia in primary mesencephalic cultures, which in turn amplify a-synuclein-mediated neurotoxicity (Zhang et al., 2005). The phagocytosis of extracellular aggregated a-synuclein and activation of NADPH-oxidase is essential to further activate microglia and propel DA neurodegeneration (Zhang et al., 2005). Neuromelanin, a neuro-pigment released from stressed DA neurons has been shown to induce microglial activation (Wilms et al., 2003) through proteasomal inhibition (Kim et al., 2006). Its accumulation in human SNpc correlates with age progression, and extra neural melanin has been found in close proximity to activated microglial cells in patients suffering from juvenile idiopathic and methyl-4-phenyl-2,3-dihydropyridine (MPTP)-induced Parkinsonism (Wilms et al., 2007). Supplementation of microglial cultures with human neuromelanin in vitro has been shown to induce chemotactic effects and stimulate the release of TNFa, IL-6 and NO (Wilms et al., 2003). Thus, the release of neuromelanin can augment microglial activation and contribute to a self-perpetuating cycle of neuronal degeneration and chronic inflammation (Kim et al., 2006). Extracellular ATP, a purinergic neurotransmitter, was initially described as an activator of microglial cells in 1993 (Kettenmann et al., 1993). The effects of ATP released from damaged neurons are mediated through its signalling with purinergic receptors, namely the metabotropic G-protein coupled P2Y receptors and the ligand gated ionotropic P2X receptors, both of which are expressed on microglia (Butt, 2011). Upon stimulation, activated microglia migrate along a chemotactic gradient to the site of injury or inflammation, facilitated by the release of promigratory factors such as extracellular ATP, UTP and members of the chemokine family from damaged cells. ATP then interacts with P2 receptors on microglia to stimulate the release of TNFa, IL-1 $\beta$, iNOS and NO. Experiments by Kim et al have identified a pivotal role for the protease MMP-3 in DA neuronal activity (Kim et al., 2005). MPP+-stressed primary mesencephalic DA neurons induce and release active MMP-3, which is toxic to DA 
neurons. It has been reported that primary microglial cultures treated with catalytically active recombinant MMP-3 stimulated microglial activation, superoxide generation and enhanced DA neuronal cell death while MPTP-treated MMP-3/- mice attenuated microglial activation, superoxide generation and DA degeneration (Kim et al., 2007).

Stimulation with the glycolipid endotoxin lipopolysaccharide (LPS) is currently one of the most common methods for activating microglia in vitro. LPS interacts with Toll-like receptor (TLR) 4, one of a family of pathogen recognition receptors (PPRs) responsive to microbial signals. Microglia have been reported to express 9 of the 12 TLRs (Jack et al., 2005). LPSstimulated microglia release inflammatory cytokines (IL-1 $\beta$, IL-1 receptor antagonist (IL1RA), IL-6, IL-8, IL-10, IL-12, IL-18, macrophage colony stimulating factor), chemokines (macrophage inflammatory protein (MIP)-1a, MIP-1 $\beta$, TNF- $\alpha$, TNF- $\beta$, monocyte chemoattractant protein-1 (MCP-1), RANTES), and prostaglandins (Kim \& de Vellis, 2005; Nakamura, 2002), as well as stimulating an increase in myristoylated alanine-rich $C$ kinase substrate (MARCKS), MARCKS-related protein, protein kinase-C, iNOS and NO production (Garden \& Moller, 2006). Cytokines produced by LPS-stimulated microglia can potentiate microglial activation through autocrine signalling to create a self-propagating cycle of expression. Pro-inflammatory cytokines IL-1 $\beta$, TNFa, IL-2 and IL-6 are constitutively expressed at basal levels in PD patients as evidenced in post-mortem, serum and cerebrospinal fluid in vivo (Boka et al., 1994; Dobbs et al., 1999; Mogi et al., 1994a; Mogi et al., 1994b; Stypula et al., 1996). Moreover, the death signalling receptor TNF receptor type-1 (TNFR-1) is expressed on DA neurons in human SNpc (Boka et al., 1994; Mogi et al., 2000). Animal studies support an involvement of pro-inflammatory cytokines in the DA neuronal degeneration evident in PD. For example, induction of chronic expression of IL-1 $\beta$ in adult rat $\mathrm{SNpc}$ using a recombinant adenovirus resulted in DA neuronal cell death after three weeks (Ferrari et al., 2006). Another study using neutralising antibodies to IL-1 $\beta$ and TNF- $\alpha$ showed that approximately $50 \%$ of LPS-induced DA neuronal cell death in primary cultures of rat midbrain was mediated by the production of these two cytokines (Gayle et al., 2002).

It has been postulated that microglia are maintained in a quiescent state by numerous microenvironmental inhibitory influences, many of which are produced by neurons. Hence, microglial activation during pathological insult may be due to a "switching-off" of these inhibitory neuronal signals (Ransohoff \& Cardona, 2010). One such neuron-cell inhibitory signalling mechanism is the direct cell-to-cell interactions between neuronal-CD200 (OX2) and its receptor CD200R, expressed on microglia. The CD200-CD200R interaction is essential for maintaining microglial homeostasis in the unperturbed CNS. A down-regulation of CD200 expression has been observed in neurons exposed to inflammatory conditions, and inhibition of CD200 causes microglial activation (Lyons et al., 2007). Therefore, there is a direct neuronal mechanism for regulating microglial activity, and loss of this interaction during neuronal cell degeneration may stimulate up-regulation of CD200, facilitating microglial activation. Recent evidence has implicated an impairment of CD200-CD200R interaction as a contributing factor in PD neurodegeneration (Wang et al., 2011). Blockade of CD200R selectively and significantly enhanced DA neuronal cell susceptibility to rotenone and iron-induced neurotoxicity in mesencephalic neuron-glia co-cultures. This was coupled with elevated microglial activation and superoxide generation and a decrease in CD200 expression on DA neurons. Microglia have also been shown to receive inhibitory inputs from a neuronal membrane-tethered chemokine $\mathrm{CX}_{3} \mathrm{CL1}$, through its receptor $\mathrm{CX}_{3} \mathrm{CR}$. Removal of this inhibition also unleashed microglial activity (Shan et al., 2011). Other inhibitory signals exist between CD22-CD45, CD172A-CD47 and ICAM5-LFA-1 (Ransohoff \& Perry, 2009). 


\section{Systemic inflammation and Parkinson's disease}

It has been proposed that in chronic neurodegenerative diseases like PD, systemic infections and inflammation can exacerbate symptoms and promote neurodegeneration (Perry et al., 2007). A systemic response includes the liver acute phase response and the behavioural and metabolic components that induce sickness behaviour (Ferrari \& Tarelli, 2011; Perry et al., 2007). Specifically, peripheral monocytes, macrophages and Kupffer cells express TLRs and PPRs, which innately recognise specific pathogen-associated molecular patterns (PAMPs) associated with invading pathogens (Dantzer, 2009). A prototypical PAMP, LPS, is specifically recognised by TLR4, which results in the production of pro-inflammatory cytokines IL-1a, IL-1 $\beta$. Through autocrine signalling these cytokines induce self-synthesis and the synthesis of further cytokines (Dantzer, 2009) inducing general inflammation. Compromise of the blood-brain barrier (BBB) which is observed in neurological disorders, stimulates peripheral leucocytes and systemic inflammatory mediators such as cytokines, to migrate into the brain parenchyma where they induce the activation of microglia and the subsequent release of more cytokines (Ferrari \& Tarelli, 2011). For example, peripheral TNFa can stimulate microglia to secrete chronically elevated pro-inflammatory mediators, which in turn can induce chronic self-perpetuating neuroinflammation, resulting in a slow and progressive loss of DA neurons in the SNpc (Qin et al., 2007). The brain recognises cytokines as molecular signals of sickness and induces symptoms of malaise, lassitude, fatigue, anhedonia, apathy, numbness, coldness, and reduced appetite and body temperature (Dantzer, 2009; Perry et al., 2007). To reinforce this theory, it has been demonstrated that a systemic inflammatory challenge in an animal with chronic neurodegeneration exhibits exaggerated brain inflammation, sickness behaviour and an increase in acute neurodegeneration (Perry et al., 2007). This emerging "two-hit hypothesis" in the aetiology of neurodegenerative diseases such as PD, suggests that the disease is multifactorial and a consequence of "multiple-hits" involving diverse inflammatory stimuli (Di Monte, 2003). Infectious agents may comprise the first "hit", therefore sensitising the brain to subsequent "hits", which may not have been pathogenic in the absence of an already "primed" system (Jang et al., 2009a). In this instance, microglia in the aged or diseased brain are said to be "primed" and can evoke an exaggerated response contributing to disease progression (Perry et al., 2007).

Clinical and epidemiological reports suggest a correlation between systemic inflammatory events, chronic neuroinflammation and the aetiology and progressive nature of PD (Ferrari \& Tarelli, 2011; Long-Smith et al., 2009; Perry, 2010). Postulated risk factors implicated in idiopathic PD include age, genetic predisposition, bacterial or viral infections, neuronal injury such as traumatic brain injury or stroke, and environmental toxins (Koprich et al., 2008; Tansey \& Goldberg, 2010). Associations were first established towards the end of the first world war (1924-1918) when the H1N1 influenza-A pandemic was coupled with a dramatic increase in post-encephalitic Parkinsonism (PEP) (also referred to as "sleeping sickness" or von Economo encephalitis) (Jang et al., 2009a; Rail et al., 1981; Tansey et al., 2007). People born during this time were at a 2-3 fold increased risk of developing PD, with PEP implicated in 50\% of all Parkinsonism cases (Jang et al., 2009a; Tansey et al., 2007). PEP shares cardinal symptomatology with idiopathic PD including rigidity and bradykinesia but a lack of Lewy body formation (Jang et al., 2009a). Moreover, Takahashi et al., 1995 demonstrated that the H1N1 virus preferentially targets the SNpc, the primary site of pathology in PD (Takahashi et al., 1995). It has also been shown that exposure to the highly 
pathogenic neurotropic H5N1 influenza virus increases susceptibility to developing PD with an observed onset of post-influenzal encephalopathies (Jang et al., 2009b). Other viruses associated with secondary Parkinsonism include coxsackie virus (Poser et al., 1969; Walters, 1960), Japanese encephalitis B (Ogata et al., 1997), St. Louis virus (Pranzatelli et al., 1994), west Nile virus (Robinson et al., 2003) and HIV (Tse et al., 2004). Infection with Japaneseencephalitis virus (JEV), which occurs predominantly in India, China and Southeast Asia, for a prolonged period is likely to induce PEP (Ogata et al., 2000; Shoji et al., 1993; Tansey et al., 2007). People with JEV have similar neuropathological and locomotor symptoms to patients with idiopathic PD (Tansey et al., 2007), and the virus has previously been used to create a pre-clinical model of PD in rats (Ogata et al., 1997). This group demonstrated that in Fisher rats infected with JEV, there was marked gliosis and DA neuronal loss in the SNpc similar to that seen in PD, and bradykinesia which could be reversed with L-DOPA and monoamine oxidase (MAO) inhibitors. More recently, in a cohort of 60 JEV patients, transient-type Parkinsonian features were observed in 16 patients, with 19 displaying Parkinsonism with additional dystonia (Misra \& Kalita, 2010).

Oxidative stress, through the generation of reactive oxygen species (ROS) is a key regulator of the neuroinflammatory process, with the underlying purpose of removing the cause of inflammation. Progressive neurodegenerative diseases like PD however, are associated with an overproduction of ROS causing neuronal oxidative damage as well as microglial activation, which subsequently leads to the generation of more ROS (Block \& Hong, 2005). Moreover, oxidative stress preferentially affects DA neurons in the SNpc, which are particularly vulnerable as they operate under high oxidant conditions due to reduced levels of the anti-oxidant glutathione (Misra \& Kalita, 2010; Sian et al., 1994). Accordingly, it has been postulated that pre-exposure to environmental toxins such as heavy metals, organophosphate compounds, neurotoxins, and pesticides like paraquat and rotenone which can induce oxidative stress and the generation of free radicals, increases the susceptibility to the development of PD in later life (Calne \& Langston, 1983; Jang et al., 2009a). Pathological and clinical evidence has also identified the involvement of the gastrointestinal tract in enhancing susceptibility to idiopathic Parkinsonism, with Helicobacter pylori infection proposed as a potential trigger in disease progression (Tansey \& Goldberg, 2010; Weller et al., 2005). Indeed, polymorphisms in the nucleotide-binding oligiomerisation domain 2 (NOD2) gene associated with Crohn's disease, a chronic inflammatory bowel disease, have been shown to be over-represented in patients with idiopathic PD (Bialecka et al., 2007).

Evidence now suggests that a disruption in neurovascular homeostasis with increased BBB permeability due to factors secreted by activated glia is associated with neuroinflammation in age-related neurodegenerative diseases. Activated glia have an up-regulated expression of cellular adhesion molecules and the subsequent induction of chemokine gradients direct peripheral leucocytes to the site of inflammation (Chung et al., 2010; Stone et al., 2009). Indeed, positron emission tomography (PET) and histological studies of PD patients as well as MPTP and LPS-induced models of PD reveal a pathogenic link between neuroinflammation, increased BBB permeability and the consequent infiltration of systemic inflammatory molecules, and DA neuronal death (Chung et al., 2010). PD patients have a reported dysfunction in the BBB transporter system (Kortekaas et al., 2005) and blood vessels in the midbrain (Faucheux et al., 1999). Increased levels of vascular endothelial growth factor (VEGF) and pigment epithelium-derived factor have been demonstrated in PD patients and in the MPTP model (Yasuda et al., 2007). A report from a study using 
animals provides evidence that nigral injection of VEGF to mice disrupted the BBB permeability and induced DA neuronal death in the ventral mesencephalon (VM) (X. Chen et al., 2008). In another study, systemic injection of high concentrations of LPS to rats caused functional breakdown of the BBB resulting in granulocyte infiltration and activation of parenchymal microglia. The subsequent infiltration of immune cells contributed to the degeneration of DA neurons in the SNpc (Brochard et al., 2009).

Assessment of serum obtained from PD subjects corroborates the involvement of systemic inflammation in PD (Hirsch \& Hunot, 2009). Increased levels of CD4 ${ }^{+}$have been reported in the serum of patients with PD, suggesting peripheral activation of lymphocytes (Bas et al., 2001; Fiszer et al., 1994; Hirsch \& Hunot, 2009). Infiltrating cytotoxic CD4 ${ }^{+}$and CD8 ${ }^{+} \mathrm{T}$ cells, but not B cells, have been observed in the inflamed SNpc of post-mortem PD human specimens and in the MPTP-induced mouse model of PD during the course of neurodegeneration (Brochard et al., 2009; Ferrari \& Tarelli, 2011; Stone et al., 2009). In support of a role for systemic immune cells in the degeneration of nigral DA neurons, CD4-/mice have been shown to be resistant to MPTP-induced neurotoxicity in the SN (Brochard et al., 2009). Amplified TNFa, IL-2, IL-6 and RANTES (Brodacki et al., 2008; Dobbs et al., 1999; Rentzos et al., 2007; Stypula et al., 1996) levels have also been detected in serum obtained from PD patients. Increases in serum cytokines may serve as a therapeutic marker for PD as a blood sample study of men with high plasma concentrations of IL-6 revealed an increased risk of developing PD (H. Chen et al., 2008). In a cohort of 46 PD patients, increased serum levels of soluble TNFR-1, which modulates TNFa activity were detected, which is in agreement with studies showing elevated TNFR-1 in the SNpc of PD brains (Mogi et al., 2000), although this was not associated with clinical parameters. Another group however, has demonstrated that LPS-induced increase of MCP-1, RANTES, MIP-1a, IL-8, IL-6 and IFN $\gamma$ levels secreted by peripheral blood mononuclear cells significantly correlated with the severity of PD symptoms (Reale et al., 2009). Systemic low level of inflammation induced by a non-toxic dose of LPS has been shown to increase the severity of nigral DA neuronal cell loss in response to a subsequent low-dose of 6-OHDA in the rat model of PD (Koprich et al., 2008), while chronic systemic IL-1 $\beta$ also exacerbated neurodegeneration and microglial activation in the SN of 6-OHDA-treated rats (Pott Godoy et al., 2008). These data support the role of primed microglia, in the "two-hit hypothesis".

Evidence now suggests that prenatal infections may be a risk factor for the development of $\mathrm{PD}$ in later life. Brains from postnatal day (P) 21 rat pups born to dams that were intraperitoneally injected with LPS at the gestation window of vulnerability (embryonic day (E) 10.5), displayed reduced numbers of tyrosine hydroxylase (TH) immunoreactive cells in the SN and ventral tegmental area. This apparent DA neuronal loss was associated with reduced striatal dopamine and an increase in TNFa in the striatum and mesencephalon. The loss of $\mathrm{TH}^{+}$cells was still observed 33 days post- injection (Ling et al., 2002). It has thus been suggested that prenatal infections such as bacterial vaginosis (BV) in humans may be potential risk factors for PD. Indeed, during pregnancy, levels of LPS and TNFa are elevated in the chorioamniotic environment of women with BV, which may hinder typical DA neuron development (Ling et al., 2002). One group has reported loss of DA neurons up to 16 months post prenatal exposure of rats to LPS, which corresponds to the mean age in humans at which PD symptoms are first observed. Thus, prenatal exposure of rats to LPS has been suggested as a potential model of PD as it induces a slow, protracted loss of nigral DA neurons (Carvey et al., 2003). Further validation for this model was demonstrated by 
significant dopamine and serotonin reductions observed in the frontal cortex, nucleus accumbens, striatum, amygdala, hippocampus and hypothalamus, comparable to the neurochemical alterations evident in PD subjects (Wang et al., 2009). In a study to examine the effect of systemic inflammation on the progression of PD, prenatally LPS-exposed rats were subjected to a moderate dose of 6-OHDA at four-months. The data revealed that both prenatal LPS exposure and postnatal 6-OHDA-treatment produced significant DA neuron loss. However, the combined effect was additive and not synergistic. This may have been due to the young age of the animal or the toxin used (Ling et al., 2004). This model was subsequently investigated but with prenatally LPS-exposed rats treated with rotenone rather than 6-OHDA postnatally. The combined effects of LPS and rotenone produced a synergistic $\mathrm{TH}^{+}$cell loss in the $\mathrm{SN}$ relative to controls, which was associated with increased striatal-dopamine activity, TNFa and increased reactive microglia (Ling et al., 2004).

\section{Inflammation in animal models of Parkinson's disease}

\subsection{MPTP model}

The MPTP model of PD has been extensively used to elucidate the basal ganglia response to nigrostriatal deficits as well as to examine the validity of novel drug treatments for PD. The MPTP neurotoxin was initially discovered during the 1980s in humans intoxicated with a by-product of an illicit drug synthesis scheme who presented with symptoms manifesting as severe Parkinsonism (Langston et al., 1983; Langston \& Ballard, 1983). Post-mortem analysis, ranging between 3-16 years post-MPTP administration, revealed selective DA neurodegeneration and gliosis, with microglial clustering occurring around nerve cells (Langston et al., 1999). It was subsequently postulated that activated microglia might perpetuate DA neuronal degeneration after a primary insult of environmental or genetic origin (Hirsch et al., 2003). Currently, MPTP administration is the most universally used agent for reproducing PD pathologies. It is primarily used in murine and non-human primate models of PD but less frequently in rats, as rat DA neurons are elusively resistant to MPTP-toxicity and are incapable of recapitulating analogous symptoms (Przedborski \& Vila, 2003). Motor-impairment symptoms of PD such as bradykinesia, tremor at rest, gait disturbances, postural instability and rigidity have all been observed in MPTP-treated primate models (Bove et al., 2005). While MPTP can mimic a wide range of PD-like symptoms it does not manifest one of the pathological hallmarks of PD, namely the formation of Lewy body-like inclusions, nor can it induce sustained motor impairments. MPTP is highly lipophilic and can easily infiltrate the BBB where it is spontaneously oxidised to an active form, 1-methyl-4-phenyl-2,3-dihydropyridium (1-MPP+) by MAO-B in glial cells. 1-MPP+ is released into the extracellular space where it is taken up by DA neurons via the DA transporter (DAT) (Przedborski \& Vila, 2003). Here, it accumulates in the mitochondrial complex and is involved in potently inhibiting mitochondrial complex-1 of the electron transfer chain, leading to an increased production of ROS such as $\mathrm{O}_{2}{ }^{-}$and a decrease in ATP. In addition, 1-MPP+ can bind to vesicular monoamine transporter-2, enabling its translocation into the synaptic vesicles where it stimulates the extrusion of synaptic DA. This excess DA is auto-metabolised resulting in a burst of ROS such as hydrogen peroxide $\left(\mathrm{H}_{2} \mathrm{O}_{2}\right)$ and superoxide radicals $\left(\mathrm{O}_{2}^{-}\right)$. Accumulation of ROS subsequently causes oxidative degradation of DNA, lipids and proteins resulting in the demise of nigral neurons. This MPTP-induced burst of ROS is generated by microglial 
$\mathrm{NADPH}$, therefore, activated microglia have been shown to play an essential role in MPTPinduce neurotoxicity (Gao et al., 2003; Wu et al., 2003). Moreover, cytosolic DA oxidation can be catalysed by COX-2, which has been shown to be up-regulated in nigral DA neurons in both MPTP-treated mice, rats and in human post-mortem samples (Teismann \& Ferger, 2001; Teismann et al., 2003).

In an effort to examine a potential role for glia in DA neuronal degeneration, focus was initially placed on deciphering the temporal relationship between DA neurodegeneration and glial activation in MPTP-induced PD murine models. Significant depletion of DA fibres and activated astroglia in the striatum was observed 24-48 hours and 48 hours post-MPTPadministration, respectively (O'Callaghan et al., 1990). The duration of astroglia activation was directly dependent on the extent of DA neuronal damage, and was sustained for the duration of MPTP-administration. It was subsequently reported that microglial activation was observed in the striatum 48 hours post-MPTP administration (Francis et al., 1995), while further studies elucidated that activated microglia were present in the SNpc 24 hours post MPTP and that activation was sustained for 14 days (Czlonkowska et al., 1996; Kohutnicka et al., 1998). Other groups pinpoint microglial activation in the SN of mice as early as 12 hours and peaking at 24 hours post-MPTP-administration (Dehmer et al., 2000; Liberatore et al., 1999). It has since been reported that activated amoeboid microglia have been observed in the SN of monkeys years after systemic MPTP-injection (McGeer et al., 2003). A further study has implicated a role for cytokines and chemokines in the acute MPTP mouse model of PD by demonstrating that real-time PCR detected elevated mRNA expression of TNFa, MCP-1 and IL-1a in the mouse striatum 2-4 hours post MPTP-administration (Sriram et al., 2006). However, ablation of TNF $\alpha$ or TNFR-1 did not affect chronic MPTP-induced nigral DA neuronal cell degeneration in mice (Ferger et al., 2004; Leng et al., 2005).

\subsection{6-OHDA model}

6-OHDA is a hydroxylated analogue of DA, which is actively taken up into DA neurons via DAT expressed on the nerve terminals. It is directly toxic to DA neurons and is used to model PD in rodents. However, since it is unable to cross the BBB, it must be stereotaxically injected into the $\mathrm{SN}$, which results in a widespread and almost immediate destruction of DA neurons (Stanic et al., 2003). The standard delivery method of 6-OHDA is unilateral injection into either the $\mathrm{VM}$, the medial forebrain bundle or the striatum, avoiding areas containing noradrenergic neurons as 6-OHDA can be taken up via the noradrenaline transporter (Deumens et al., 2002). Striatal lesions result in destruction of the nigral DA neuronal terminals leading to a dying back mechanism whereby the cell bodies in the SN are affected secondarily and progressively (Kirik et al., 1998; Sauer \& Oertel, 1994). This creates a therapeutic window of opportunity whereby potential neuroprotective strategies can be evaluated. Loss of $\mathrm{TH}^{+}$-immunoreactive cells are detectable as early as 24 hours post-6OHDA lesion in the striatum, peaking in the third week post-lesion. However, loss of $\mathrm{TH}^{+}$ cells in the SN does not appear until the second week post-lesion (Blandini et al., 2007). Behavioural testing such as drug-induced rotations can then be performed to assess the antiParkinsonian abilities of potential therapies. While the 6-OHDA-lesion model remains one of the most popular animal models of PD to date, like the MPTP model, it fails to encapsulate all the hallmarks of PD pathology, particularly a lack of Lewy body formation. Secondly, PD is a chronic disorder potentially lasting 1-2 decades, so the 6-OHDA-model is in fact regarded as an acute model of PD. As in the MPTP-induced animal model of PD, 
activated microglia have been observed in the SN and nigrostriatal tract of 6-OHDAlesioned rats (Akiyama \& McGeer, 1989; Depino et al., 2003; He et al., 2001). Microglial activation was initially observed 1-day post 6-OHDA-lesion but appeared transient in nature (Akiyama \& McGeer, 1989). We have observed a significant increase in the number of activated microglia, indicated by MHC class II in the SNpc of 6-OHDA-lesioned rats at 10-28 days post lesion (Crotty et al., 2008). Pro-inflammatory cytokines have also been implicated as neurotoxic mediators of 6-OHDA-induced DA neuronal death; blockade of the soluble form of the TNF-a receptor but not the transmembrane form was found to attenuate the death of DA neurons in 6-OHDA-lesioned rats (McCoy et al., 2006). We have previously demonstrated that conditioned-medium (CM) obtained from LPS-stimulated rat glialenriched cortical cultures can induce loss of DA neurons in primary VM cultures and that this effect can be exacerbated by 6-OHDA treatment. IL-1 $\beta$ released from activated microglia in the CM mediated this effect as blockade of IL-1R1 with IL-1RA attenuated the CMinduced DA neuronal toxicity (Long-Smith et al., 2010).

\subsection{LPS model}

LPS is one of the main constitutes of gram-negative bacteria and is used as a tool to mimic general infection as it is a potent stimulator of immune cells. Intranigral injection of LPS in rats has been shown to manifest Parkinsonism-like symptoms, such as the selective loss of DA neurons in the SN (Arimoto et al., 2006; Castano et al., 1998; Herrera et al., 2000). Thus the LPS model has served as a valuable tool in deciphering the role of glial cells, especially microglia, in the DA neurodegeneration process and has been described by many as the neuroinflammatory model of PD. LPS binds to the serum LPS-binding protein (LBP), which facilitates binding to the CD14 receptor expressed on microglia. The LBP can then dissociate and allow the LPS-CD14 complex to bind to TLR4, resulting in a cascade of intracellular signalling. The adapter protein myeloid differentiation factor 88 (myD88) attaches to TLR4 and interacts with IL-1 receptor-associated kinase (IRAK), which phosphorylates, activating TNF-R-associated factor-6 (TRAF6). The mitogen-activated protein kinases (MAPK) p38 and c-Jun N-terminal kinase (JNK) are activated downstream of this, leading to the upregulation of transcription factors such as nuclear-factor- $\mathrm{kB}(\mathrm{NF}-\mathrm{kB})$. This up-regulation results in the production of pro-inflammatory cytokines (McGettrick \& O'Neill, 2010).

Intranigral injection of LPS in rats has been shown to result in a significant decrease of DA levels in the striatum, microglial activation and a time and LPS-dose-dependent degeneration of DA neurons in the SN (Castano et al., 1998). In this study, microglial activation was observed at 6 hours and peaked at 1-2 days post LPS injection, while DA neuronal degeneration persisted up to at least 21 days after intranigral injection of LPS demonstrating that LPS-induced microglial activation can induce progressive degeneration of nigral DA neurons. Furthermore, it has been reported that prenatal exposure of LPS to rats results in sustained microglial activation and the development of fewer than normal nigral DA neurons (Ling et al., 2006). Systemic administration of LPS has also been found to induce progressive degeneration of nigral DA neurons in rats (Qin et al., 2007). It had previously been suggested that LPS-mediated DA neuronal toxicity required the presence of glia (Bronstein et al., 1995) and indeed a subsequent study reported that a single intranigral injection of LPS induced selective DA neuronal degeneration up to one year post injection (Herrera et al., 2000). Thus, unlike MPTP and 6-OHDA, LPS is not a direct toxin but rather causes indirect death of DA neurons by activating microglia, inducing an inflammatory 
reaction and subsequent DA neuronal death. Studies on rat mesencephalic cultures suggest that DA neurons are twice as sensitive to LPS as non-DA neurons and that the toxicity of LPS occurs via microglial activation (Bronstein et al., 1995; Gayle et al., 2002). Although many in vitro studies have supported an involvement of $\mathrm{NO}$ in microglial-mediated DA neuronal death after LPS-treatment (Chao et al., 1992; Gibbons \& Dragunow, 2006), others have suggested that NO is not involved (Castano et al., 1998; Gayle et al., 2002). The proinflammatory cytokines IL-1 $\beta$ and TNF- $\alpha$ are thought to be involved in LPS-mediated toxicity (Gayle et al., 2002). In support of a role for LPS-induced pro-inflammatory cytokines in DA neurotoxicity, we have shown that IL-1 $\beta$ in CM released from LPS-stimulated microglia significantly reduces the percentage of DA neurons in embryonic rat neuronalenriched cultures that IL-1R1 is expressed on these DA neurons, and that blockade of IL-1R1 prevented the CM-induced DA neuronal death (Long-Smith et al., 2010). Furthermore, blockade of the soluble form of the TNF- $\alpha$ receptor has been reported to reduce microglial activation in the in vivo LPS model of PD (McCoy et al., 2006). Also, Ling and co-workers found that the decreased numbers of nigral DA neurons in rats after prenatal exposure to LPS, was accompanied by elevated levels of TNF- $\alpha$ in the striatum (Ling et al., 2004).

\section{Neuroinflammatory diagnostic tools for Parkinson's disease}

Microglial responsiveness to injury and neurodegenerative disease suggests that it may serve as a marker for the diagnosis and progression of disease pathology in PD. There is a current drive to develop non-invasive imaging tools to assess and quantify the dynamics of activated microglia in neurodegenerative diseases like PD. Advances in this technology, especially for identification of microglial biomarkers at the early stages of disease, would have important implications for PD diagnosis, assessment of progression, and therapy. Currently, the best-studied imaging paradigm for microglial activation is the radiolabelled translocator protein (TSPO) ligand using PET (Dolle et al., 2009). This line of research initially started when a correlation was observed between increased binding of Ro5-4864 (a benzodiazepine) and PK11195 (an isoquinoline) to receptors on the surface of mitochondria primarily localised in glial cells (Arlicot et al., 2008; Chauveau et al., 2008). These receptors were originally referred to as peripheral type benzodiazepine receptors and were increased in activated microglia (Park et al., 1996; Stephenson et al., 1995). The nomenclature has since been changed to TSPO as further research elucidated that these receptors are expressed throughout the brain and body (Papadopoulos et al., 2006). Gene-expression analysis in brains of rodents, primates and humans have illustrated that TSPO expression is nearly absent in parenchyma-microglia (Winkeler et al., 2010) but is elevated in many neurodegenerative disorders including, stroke, AD, PD, multiple sclerosis, Huntington's disease and amyotrophic lateral sclerosis, (Arlicot et al., 2008) thus emphasising the involvement of microglial activation and neuroinflammation in these diseases. TSPOs are the prototypical biomarkers of neuroinflammatory changes in a variety of CNS disorders and have therefore been proposed as potential diagnostic targets for in vivo imaging (Arlicot et al., 2008; Chauveau et al., 2008).

Currently, functional PET and single photon emission tomography (SPECT), in conjunction with ligands for TSPO, can detect microglial activation in vivo. Examples of radiolabelled TSPO ligands include [ $\left.{ }^{11} \mathrm{C}\right]$ Ro5-4864 and [11C](R)-PK11195 (1-(2-chlorophenyl)-N-methyl-N(1-methylpropyl)-3 isoquinoline carboxamide) (Chauveau et al., 2008). In PD subjects, PET 
imaging revealed microglial activation in the pons, basal ganglia, and frontal and temporal cortical areas. Longitudinal studies of these patients revealed stable [11C](R)-PK11195 binding potential (BP; a parameter that mixes receptor density with ligand affinity), indicative of early activation of microglia in PD pathology (Gerhard et al., 2006; Winkeler et al., 2010). However, the $\left[{ }^{11} \mathrm{C}\right](R)-\mathrm{PK} 11195$ tracer is limited, as it is incapable of distinguishing between phenotypic differences, and thus possibly functional differences of microglia. To overcome this, a PET tracer for the dopamine-transporter, $\left.{ }^{11} \mathrm{C}\right] \mathrm{CFT}$, has been used in conjunction with $\left[{ }^{11} \mathrm{C}\right](R)-\mathrm{PK} 11195$ to examine the viability of the presynaptic DA neurons (Ouchi et al., 2009). This study of 10 drug-naïve PD patients, demonstrated changes in microglial activity in conjunction with DAT density which were investigated using PET imaging with $\left[{ }^{11} \mathrm{C}\right](R)-\mathrm{PK} 11195$ and $\left[{ }^{11} \mathrm{C}\right] \mathrm{CFT}$ tracers. Subjects underwent magnetic resonance imaging (MRI) prior to PET measurement to define the regions of interest, which would allow for the evaluation of microglial activation in parallel with presynaptic neuronal degeneration in vivo. Elevated midbrain $\left[{ }^{11} \mathrm{C}\right](R)$-PK11195 BP levels were significantly inversely correlated with $\left[{ }^{11} \mathrm{C}\right] \mathrm{CFT}$ BP localised in the putamen. The elevated $\left[{ }^{11} \mathrm{C}\right](R)-$ PK11195 BP also correlated with motor impairment. A follow-up 4-year scan revealed increased microglial activation spread over the extrastriatal region (Ouchi et al., 2009). PET imaging and post-mortem analysis of the brain of a rat lesioned with 6-OHDA revealed reduced $\left[{ }^{11} \mathrm{C}\right] \mathrm{CFT} \mathrm{BP}$ in the striatum, indicative of DA degeneration, while $\left[{ }^{11} \mathrm{C}\right](R)-\mathrm{PK} 11195$ $\mathrm{BP}$ was markedly increased in the striatum and SNpc. Post-mortem immunohistochemical analysis corroborated this finding by showing activated microglia in the striatum and SNpc at 4 weeks post-lesion (Cicchetti et al., 2002). Alternative SPECT imaging biomarkers for TSPO such as [123I]CLINDE (2-(4'iodophenyl)-3-(N,N-diethyl)-imidazo[1,2-a]pyridine-3acetamide) have been examined in vivo and also pose as potential image-guided diagnostic tools for microglial activation in neurodegenerative diseases like PD (Arlicot et al., 2008).

\section{Immunomodulatory therapies}

As the wealth of evidence continues to accumulate regarding the role of microglial activation in the pathogenesis of $\mathrm{PD}$, a large number of inhibitory drugs have been investigated. The use of broad spectrum steroidal and non-steroidal anti-inflammatory drugs, specific microglial inhibitors or anti-inflammatory cytokines have not only helped decipher the role of microglial activation in neuroinflammation in PD but also indicated that inhibiting the specific processes involved in microglial activation may be a therapeutic avenue for PD.

The glucocorticoids are well known for their broad range of anti-inflammatory effects and have long been used in clinical settings for the treatment of brain inflammation (Castano et al., 2002). Microglial cells express the glucocorticoid receptor which is involved in the regulation of the transcription factors NF- $\mathrm{kB}$ and activator protein-1 (AP-1) (Scheinman et al., 1995) which in turn are key regulators of pro-inflammatory cytokine expression (Nadeau \& Rivest, 2003). Of particular interest, the synthetic steroid dexamethasone was shown to provide neuroprotection against LPS or MPTP-induced toxicity in rodent models. In both models, the delivery of dexamethasone prevented the activation of microglia usually associated with neurodegeneration (Castano et al., 2002; Kurkowska-Jastrzebska et al., 2004). However, the severe side-effects associated with glucocorticoid use prevent any long-term usage in neuroprotective therapies for PD. Large scale epidemiological studies have shown 
that the chronic use of non-steroidal anti-inflammatory drugs (NSAID) such as aspirin or ibuprofen could provide some level of protection against PD (Chen et al., 2005; Chen et al., 2003). Other studies suggest that the role of NSAIDs in decreasing the risk of PD is extremely limited (Hancock et al., 2007; Hernan et al., 2006). A recent meta-analysis of studies published between 1966 and 2008 showed that while NSAIDs as a class do not modify the risk of developing PD, the chronic intake of ibuprofen may have a beneficial effect (Gagne \& Power, 2010; Gao et al., 2011; Samii et al., 2009). Ibuprofen possibly mediates this effect via its inhibition of COX activity to inhibit the production of pro-inflammatory lipid mediator prostaglandins (Mitchell et al., 1993). Some of the beneficial effects observed could also be mediated via other mechanisms associated with NSAIDs such as inactivation of the pro-inflammatory nuclear receptor NF-kB (Grilli et al., 1996; Kopp \& Ghosh, 1994), activation of peroxisome proliferator-activated receptor gamma (PPARY), a nuclear factor mediating anti-inflammatory effects in microglia (Bernardo et al., 2005) or activation of the Rho kinase pathway (Zhou et al., 2003). Results from animal models of PD demonstrate that aspirin and indomethacin have both been shown to prevent MPTP-induced loss of striatal dopamine in the mouse (Aubin et al., 1998; Kurkowska-Jastrzebska et al., 2002). The NSAID Celecoxib reversed striatal DA neuronal fibre and nigral DA neuronal cell loss in 6-OHDAtreated rats (Sanchez-Pernaute et al., 2004) while aspirin has been shown to prevent 6OHDA-induced striatal dopamine depletion (Di Matteo et al., 2006).

Other neuroimmunomodulatory strategies include the use of the second generation tetracycline analogue, minocycline. It has been shown to inhibit microglial activation and prevent iNOS and NADPH oxidase generation as well as IL-1 $\beta$ up-regulation (Du et al., 2001). It is a lipophilic molecule which easily crosses the BBB and is reported to have antiinflammatory and neuroprotective activities (Kim \& Suh, 2009). Some studies in experimental models of PD have shown that it is neuroprotective against MPTP-, LPS, or 6OHDA induced neurodegeneration (Du et al., 2001; He et al., 2001; Tomas-Camardiel et al., 2004; $\mathrm{Wu}$ et al., 2002) while others showed that it exacerbated the deleterious effects of MPTP in rodents and non-human primates (Diguet et al., 2004; Yang et al., 2003). While the reason for the discrepancies is unknown, differences between the various studies include doses and timing of intervention and may reflect the dual role of microglia in inflammation. Despite these contradictory results, a phase II randomized double-blind futility clinical trial was set-up. Results after 12 and 18 months suggest that minocycline is well tolerated and does not negatively impact on symptomatic treatment. It is therefore currently recommended for phase III clinical trials to assess its long-term effect on disease progression (NINDS-NET-PD-Investigators, 2006, 2008).

In addition to the role of glial-associated innate immunity, an adaptive immune response may also be involved in triggering cell death in DA neurons. Manipulating this adaptive response mediated by $\mathrm{T}$ cells could be a successful approach for neuroprotection. This immuno-intervention aims at redirecting the harmful $\mathrm{T}$ cell response towards an antiinflammatory and protective immune response by means of an antigen-based immunisation. Preclinical results using glatiramer acetate (a random amino acid polymer composed of alanine, glutamine, lysine and tyrosine amino acids) as the immunisation agent showed that this approach could be successful. Glatiramer-acetate primed T cells transferred to MPTP-treated mice were shown to reach the brain where they suppressed microglial activation and provided neuroprotection to the nigrostriatal neurons by inducing the neurotrophic factor glial cell-derived neurotrophic factor (GDNF). Furthermore, specific 
depletion of the donor T cells abrogated this neuroprotective effect confirming that the effect is donor T cell dependent (Benner et al., 2004). Interestingly, the donor T cells were shown to secrete high levels of anti-inflammatory cytokines IL-4, IL-10 and TGF $\beta$ (Benner et al., 2004). As glatiramer acetate has already been shown to be safe and tolerable in clinical trial and has had significant reduction effects on disability in multiple sclerosis patients (Comi et al., 2011), it represents a very attractive possibility. Interestingly, another neuropeptide, vasoactive intestinal peptide, has been reported to prevent MPTP-induced loss of nigral DA neurons and striatal DA fibres in the mouse while also down-regulating IL- $1 \beta$ and TNF- $\alpha$ expression and iNOS generation (Delgado \& Ganea, 2003).

Alternatively, the delivery of anti-inflammatory cytokines such as IL-10 could be considered as an anti-inflammatory therapeutic strategy for PD. Pre-treatment of mesencephalic neuroglial cultures with IL-10 inhibited LPS-stimulated microglial activation and degeneration of DA neurons (Qian et al., 2006). Similar neuroprotective effects were observed in vivo after chronic infusion of IL-10 into the SNpc of rats that were challenged with LPS (Arimoto et al., 2006). More recently, gene therapy approaches have been developed to deliver IL-10 into the rat SNpc, and have proved effective in attenuating the neuronal loss and behavioural deficits in the 6-OHDA rat model of PD (Johnston et al., 2008). Furthermore, the blockade of pro-inflammatory cytokines should be considered as a potential therapeutic avenue. Blocking the soluble TNF signalling by delivery of a dominant-negative form has been shown to promote neuronal survival and reduce the behavioural deficits in the hemi-Parkinsonian rat model of PD (McCoy et al., 2006; McCoy et al., 2008). While these pre-clinical results are interesting, the availability of a broad spectrum of compounds acting on TNF signalling makes this molecule a very attractive target. Etanercept and Infliximab are a new generation of engineered inhibitors of TNF that are broadly used for the treatment of rheumatoid arthritis and other peripheral inflammatory diseases. Their use in CNS diseases is however limited by their general inability to cross the BBB (Tweedie et al., 2007). While direct intrastriatal delivery or long-term gene transfer as illustrated above are possibilities, other inhibitors of TNF synthesis may prove useful such as the infamous antiemetic compound thalidomide. Thalidomide is a sedative, immunosuppressive and anti-inflammatory drug that has teratogenic effects (Smithells \& Newman, 1992) and inhibits the synthesis of TNF-a (Sampaio et al., 1991). Thalidomide was shown to protect nigrostriatal neurons and prevent striatal DA depletion in the early stages of MPTP-induced neurodegeneration (Boireau et al., 1997; Ferger et al., 2004).

PPAR $\gamma$ has been shown to exert anti-inflammatory functions in both the periphery and the CNS where it is detected in glial and neuronal cells. Following activation by its naturally occurring ligands eicosanoids and prostaglandin $\mathrm{J} 2$, it regulates the expression of proinflammatory molecules such as iNOS, COX-2 and, indirectly, of broad array of cytokines through its interactions with the transcription factor NF-kB (Chaturvedi \& Beal, 2008; Chung et al., 2008). Pioglitazone and rosiglitazone are two synthetic agonists of PPARY that are approved for the treatment of type II diabetes. In the CNS they exhibit neuroprotective effects in models of neurodegenerative disorders, including PD, by preventing inflammation, oxidative damage and apoptosis (Chaturvedi \& Beal, 2008). Specifically, pioglitazone prevents MPTP-induced activation of microglia and DA neuronal cell loss in murine SNpc in vivo (Dehmer et al., 2004). This has been shown to occur through inhibition of MAO-B, the enzyme responsible for conversion of MPTP to its toxic metabolite MPP+ (Quinn et al., 2008). When pioglitazone was administered to rats that were also injected intrastriatally with LPS, the resultant LPS-induced microglial activation and DA 
degeneration was attenuated (Hunter et al., 2007). Recently, the neuroprotective effects of rosiglitazone have been shown in the MPTP mouse model of PD; chronic administration of the drug prevented behavioural deficits, DA neuronal loss and microglial activation in the SNpc in vivo (Schintu et al., 2009).

As mentioned above, NF- $\mathrm{kB}$ plays an important role in the regulation of chronic diseases through the promotion of inflammation and of cell survival. Activation of NF- $\mathrm{KB}$ requires the activity of the IKB kinase (IKK) complex (Kim et al., 2006). Activated NF-kB has been detected in neurons and activated microglia in the SN of PD patients and MPTP-treated animals suggesting that some of the pro-inflammatory mechanisms regulated by the NF- $\mathrm{KB}$ pathways may play an important role in the pathogenesis of PD (Ghosh et al., 2007; Hunot et al., 1997). Recent studies have shown that blockade of NF-kB activity either directly or through IкB can inhibit components of the inflammatory pathways in microglia namely, the oxidative stress pathway and the production of pro-inflammatory cytokines (Anrather et al., 2006; Gauss et al., 2007). Selective inhibition of NF-kB activity by a peptide blocking the IKK complex prevented DA neuronal loss in MPTP-treated mice and suppressed microglial activation (Ghosh et al., 2007). Finally, a selective pharmacological IKK $\beta$ inhibitor has demonstrated neuroprotective properties in LPS- and MPTP-induced models of PD. Treatment with this compound prevented neuronal damage in a process dependant on the presence of microglia. Particularly, it prevented the activation of microglial oxidative pathways and the release of pro-inflammatory cytokines by specific blockade of the NF-kB signalling pathway (Zhang et al., 2010).

\section{Conclusion}

The death of dopaminergic neurons in the SNpc is the key pathology of PD. Therefore, it is imperative that research is undertaken, not only in areas which could provide protective strategies for the remaining neurons, or which involve dopaminergic neuronal cell replacement therapies, but also into understanding the fundamental mechanisms by which these cells die. Although the precise role of inflammation in the pathogenesis of PD remains unclear, an array of evidence from the clinic and from animal models now points to its substantial involvement in this debilitating disease.

\section{Acknowledgment}

The authors thank Declan Conroy and Aoife Nolan for technical assistance.

\section{References}

Ajami, B., Bennett, J.L., Krieger, C., Tetzlaff, W. \& Rossi, F.M. (2007). Local self-renewal can sustain CNS microglia maintenance and function throughout adult life. Nat Neurosci, Vol.10, No.12, pp. 1538-1543

Akiyama, H. \& McGeer, P.L. (1989). Microglial response to 6-hydroxydopamine-induced substantia nigra lesions. Brain Res, Vol.489, No.2, pp. 247-253

Anisman, H. \& Merali, Z. (1999). Anhedonic and anxiogenic effects of cytokine exposure. Adv Exp Med Biol, Vol.461, No., pp. 199-233 
Anrather, J., Racchumi, G. \& Iadecola, C. (2006). NF-kappaB regulates phagocytic NADPH oxidase by inducing the expression of gp91phox. J Biol Chem, Vol.281, No.9, pp. 5657-5667

Arimoto, T., Choi, D.Y., Lu, X., Liu, M., Nguyen, X.V., Zheng, N., Stewart, C.A., Kim, H.C. \& Bing, G. (2006). Interleukin-10 protects against inflammation-mediated degeneration of dopaminergic neurons in substantia nigra. Neurobiol Aging, Vol.28, No.6, pp. 894-906

Arlicot, N., Katsifis, A., Garreau, L., Mattner, F., Vergote, J., Duval, S., Kousignian, I., Bodard, S., Guilloteau, D. \& Chalon, S. (2008). Evaluation of CLINDE as potent translocator protein $(18 \mathrm{kDa})$ SPECT radiotracer reflecting the degree of neuroinflammation in a rat model of microglial activation. Eur J Nucl Med Mol Imaging, Vol.35, No.12, pp. 2203-2211

Aubin, N., Curet, O., Deffois, A. \& Carter, C. (1998). Aspirin and salicylate protect against MPTP-induced dopamine depletion in mice. J Neurochem, Vol.71, No.4, pp. 16351642

Banati, R.B., Daniel, S.E. \& Blunt, S.B. (1998). Glial pathology but absence of apoptotic nigral neurons in long-standing Parkinson's disease. Mov Disord, Vol.13, No.2, pp. 221-227

Barron, K.D. (1995). The microglial cell. A historical review. J Neurol Sci, Vol.134 Suppl, No., pp. 57-68

Bas, J., Calopa, M., Mestre, M., Mollevi, D.G., Cutillas, B., Ambrosio, S. \& Buendia, E. (2001). Lymphocyte populations in Parkinson's disease and in rat models of parkinsonism. J Neuroimmunol, Vol.113, No.1, pp. 146-152

Bekris, L.M., Mata, I.F. \& Zabetian, C.P. (2010). The genetics of Parkinson disease. J Geriatr Psychiatry Neurol, Vol.23, No.4, pp. 228-242

Benner, E.J., Mosley, R.L., Destache, C.J., Lewis, T.B., Jackson-Lewis, V., Gorantla, S., Nemachek, C., Green, S.R., Przedborski, S. \& Gendelman, H.E. (2004). Therapeutic immunization protects dopaminergic neurons in a mouse model of Parkinson's disease. Proc Natl Acad Sci U S A, Vol.101, No.25, pp. 9435-9440

Bernardo, A., Ajmone-Cat, M.A., Gasparini, L., Ongini, E. \& Minghetti, L. (2005). Nuclear receptor peroxisome proliferator-activated receptor-gamma is activated in rat microglial cells by the anti-inflammatory drug HCT1026, a derivative of flurbiprofen. J Neurochem, Vol.92, No.4, pp. 895-903

Bialecka, M., Kurzawski, M., Klodowska-Duda, G., Opala, G., Juzwiak, S., Kurzawski, G., Tan, E.K. \& Drozdzik, M. (2007). CARD15 variants in patients with sporadic Parkinson's disease. Neurosci Res, Vol.57, No.3, pp. 473-476

Blandini, F., Levandis, G., Bazzini, E., Nappi, G. \& Armentero, M.T. (2007). Time-course of nigrostriatal damage, basal ganglia metabolic changes and behavioural alterations following intrastriatal injection of 6-hydroxydopamine in the rat: new clues from an old model. Eur J Neurosci, Vol.25, No.2, pp. 397-405

Block, M.L. \& Hong, J.S. (2005). Microglia and inflammation-mediated neurodegeneration: multiple triggers with a common mechanism. Prog Neurobiol, Vol.76, No.2, pp. 7798

Block, M.L., Zecca, L. \& Hong, J.S. (2007). Microglia-mediated neurotoxicity: uncovering the molecular mechanisms. Nat Rev Neurosci, Vol.8, No.1, pp. 57-69 
Boireau, A., Bordier, F., Dubedat, P., Peny, C. \& Imperato, A. (1997). Thalidomide reduces MPTP-induced decrease in striatal dopamine levels in mice. Neurosci Lett, Vol.234, No.2-3, pp. 123-126

Boka, G., Anglade, P., Wallach, D., Javoy-Agid, F., Agid, Y. \& Hirsch, E.C. (1994). Immunocytochemical analysis of tumor necrosis factor and its receptors in Parkinson's disease. Neurosci Lett, Vol.172, No.1-2, pp. 151-154

Bove, J., Prou, D., Perier, C. \& Przedborski, S. (2005). Toxin-induced models of Parkinson's disease. NeuroRx, Vol.2, No.3, pp. 484-494

Braak, H., Del Tredici, K., Rub, U., de Vos, R.A., Jansen Steur, E.N. \& Braak, E. (2003). Staging of brain pathology related to sporadic Parkinson's disease. Neurobiol Aging, Vol.24, No.2, pp. 197-211

Brochard, V., Combadiere, B., Prigent, A., Laouar, Y., Perrin, A., Beray-Berthat, V., Bonduelle, O., Alvarez-Fischer, D., Callebert, J., Launay, J.M., Duyckaerts, C., Flavell, R.A., Hirsch, E.C. \& Hunot, S. (2009). Infiltration of CD4+ lymphocytes into the brain contributes to neurodegeneration in a mouse model of Parkinson disease. J Clin Invest, Vol.119, No.1, pp. 182-192

Brodacki, B., Staszewski, J., Toczylowska, B., Kozlowska, E., Drela, N., Chalimoniuk, M. \& Stepien, A. (2008). Serum interleukin (IL-2, IL-10, IL-6, IL-4), TNFalpha, and INFgamma concentrations are elevated in patients with atypical and idiopathic parkinsonism. Neurosci Lett, Vol.441, No.2, pp. 158-162

Bronstein, D.M., Perez-Otano, I., Sun, V., Mullis Sawin, S.B., Chan, J., Wu, G.C., Hudson, P.M., Kong, L.Y., Hong, J.S. \& McMillian, M.K. (1995). Glia-dependent neurotoxicity and neuroprotection in mesencephalic cultures. Brain Res, Vol.704, No.1, pp. 112-116

Butt, A.M. (2011). ATP: A ubiquitous gliotransmitter integrating neuron-glial networks. Semin Cell Dev Biol, Vol.22, No.2, pp. 205-213

Calne, D.B. \& Langston, J.W. (1983). Aetiology of Parkinson's disease. Lancet, Vol.2, No.836566, pp. 1457-1459

Carson, M.J., Reilly, C.R., Sutcliffe, J.G. \& Lo, D. (1998). Mature microglia resemble immature antigen-presenting cells. Glia, Vol.22, No.1, pp. $72-85$

Carvey, P.M., Chang, Q., Lipton, J.W. \& Ling, Z. (2003). Prenatal exposure to the bacteriotoxin lipopolysaccharide leads to long-term losses of dopamine neurons in offspring: a potential, new model of Parkinson's disease. Front Biosci, Vol.8, No., pp. s826-837

Castano, A., Herrera, A.J., Cano, J. \& Machado, A. (1998). Lipopolysaccharide intranigral injection induces inflammatory reaction and damage in nigrostriatal dopaminergic system. J Neurochem, Vol.70, No.4, pp. 1584-1592

Castano, A., Herrera, A.J., Cano, J. \& Machado, A. (2002). The degenerative effect of a single intranigral injection of LPS on the dopaminergic system is prevented by dexamethasone, and not mimicked by rh-TNF-alpha, IL-1beta and IFN-gamma. J Neurochem, Vol.81, No.1, pp. 150-157

Chao, C.C., Hu, S., Molitor, T.W., Shaskan, E.G. \& Peterson, P.K. (1992). Activated microglia mediate neuronal cell injury via a nitric oxide mechanism. J Immunol, Vol.149, No.8, pp. 2736-2741

Chaturvedi, R.K. \& Beal, M.F. (2008). PPAR: a therapeutic target in Parkinson's disease. J Neurochem, Vol.106, No.2, pp. 506-518 
Chauveau, F., Boutin, H., Van Camp, N., Dolle, F. \& Tavitian, B. (2008). Nuclear imaging of neuroinflammation: a comprehensive review of [11C]PK11195 challengers. Eur J Nucl Med Mol Imaging, Vol.35, No.12, pp. 2304-2319

Chen, H., Jacobs, E., Schwarzschild, M.A., McCullough, M.L., Calle, E.E., Thun, M.J. \& Ascherio, A. (2005). Nonsteroidal antiinflammatory drug use and the risk for Parkinson's disease. Ann Neurol, Vol.58, No.6, pp. 963-967

Chen, H., O'Reilly, E.J., Schwarzschild, M.A. \& Ascherio, A. (2008). Peripheral inflammatory biomarkers and risk of Parkinson's disease. Am J Epidemiol, Vol.167, No.1, pp. 90-95

Chen, H., Zhang, S.M., Hernan, M.A., Schwarzschild, M.A., Willett, W.C., Colditz, G.A., Speizer, F.E. \& Ascherio, A. (2003). Nonsteroidal anti-inflammatory drugs and the risk of Parkinson disease. Arch Neurol, Vol.60, No.8, pp. 1059-1064

Chen, X., Lan, X., Roche, I., Liu, R. \& Geiger, J.D. (2008). Caffeine protects against MPTPinduced blood-brain barrier dysfunction in mouse striatum. J Neurochem, Vol.107, No.4, pp. 1147-1157

Chung, J.H., Seo, A.Y., Chung, S.W., Kim, M.K., Leeuwenburgh, C., Yu, B.P. \& Chung, H.Y. (2008). Molecular mechanism of PPAR in the regulation of age-related inflammation. Ageing Res Rev, Vol.7, No.2, pp. 126-136

Chung, Y.C., Ko, H.W., Bok, E., Park, E.S., Huh, S.H., Nam, J.H. \& Jin, B.K. (2010). The role of neuroinflammation on the pathogenesis of Parkinson's disease. BMB Rep, Vol.43, No.4, pp. 225-232

Cicchetti, F., Brownell, A.L., Williams, K., Chen, Y.I., Livni, E. \& Isacson, O. (2002). Neuroinflammation of the nigrostriatal pathway during progressive 6-OHDA dopamine degeneration in rats monitored by immunohistochemistry and PET imaging. Eur J Neurosci, Vol.15, No.6, pp. 991-998

Comi, G., Cohen, J.A., Arnold, D.L., Wynn, D. \& Filippi, M. (2011). Phase III dosecomparison study of glatiramer acetate for multiple sclerosis. Ann Neurol, Vol.69, No.1, pp. 75-82

Crotty, S., Fitzgerald, P., Tuohy, E., Harris, D.M., Fisher, A., Mandel, A., Bolton, A.E., Sullivan, A.M. \& Nolan, Y. (2008). Neuroprotective effects of novel phosphatidylglycerol-based phospholipids in the 6-hydroxydopamine model of Parkinson's disease. Eur J Neurosci, Vol.27, No.2, pp. 294-300

Cuadros, M.A. \& Navascues, J. (1998). The origin and differentiation of microglial cells during development. Prog Neurobiol, Vol.56, No.2, pp. 173-189

Czlonkowska, A., Kohutnicka, M., Kurkowska-Jastrzebska, I. \& Czlonkowski, A. (1996). Microglial reaction in MPTP (1-methyl-4-phenyl-1,2,3,6-tetrahydropyridine) induced Parkinson's disease mice model. Neurodegeneration, Vol.5, No.2, pp. 137143

Dantzer, R. (2009). Cytokine, sickness behavior, and depression. Immunol Allergy Clin North Am, Vol.29, No.2, pp. 247-264

Davalos, D., Grutzendler, J., Yang, G., Kim, J.V., Zuo, Y., Jung, S., Littman, D.R., Dustin, M.L. \& Gan, W.B. (2005). ATP mediates rapid microglial response to local brain injury in vivo. Nat Neurosci, Vol.8, No.6, pp. 752-758

Dehmer, T., Heneka, M.T., Sastre, M., Dichgans, J. \& Schulz, J.B. (2004). Protection by pioglitazone in the MPTP model of Parkinson's disease correlates with I kappa B alpha induction and block of NF kappa B and iNOS activation. J Neurochem, Vol.88, No.2, pp. 494-501 
Dehmer, T., Lindenau, J., Haid, S., Dichgans, J. \& Schulz, J.B. (2000). Deficiency of inducible nitric oxide synthase protects against MPTP toxicity in vivo. J Neurochem, Vol.74, No.5, pp. 2213-2216

del Rio Hortega, P. (1932). Microglia. In: Penfield, W. (Ed.), Cytology and cellular pathology of the nervous system. Hoeber, New York, pp. 481-534.

Delgado, M. \& Ganea, D. (2003). Neuroprotective effect of vasoactive intestinal peptide (VIP) in a mouse model of Parkinson's disease by blocking microglial activation. FASEB J, Vol.17, No.8, pp. 944-946

Depino, A.M., Earl, C., Kaczmarczyk, E., Ferrari, C., Besedovsky, H., del Rey, A., Pitossi, F.J. \& Oertel, W.H. (2003). Microglial activation with atypical proinflammatory cytokine expression in a rat model of Parkinson's disease. Eur J Neurosci, Vol.18, No.10, pp. 2731-2742

Deumens, R., Blokland, A. \& Prickaerts, J. (2002). Modeling Parkinson's disease in rats: an evaluation of 6-OHDA lesions of the nigrostriatal pathway. Exp Neurol, Vol.175, No.2, pp. 303-317

Di Matteo, V., Pierucci, M., Di Giovanni, G., Di Santo, A., Poggi, A., Benigno, A. \& Esposito, E. (2006). Aspirin protects striatal dopaminergic neurons from neurotoxin-induced degeneration: an in vivo microdialysis study. Brain Res, Vol.1095, No.1, pp. 167-177

Di Monte, D.A. (2003). The environment and Parkinson's disease: is the nigrostriatal system preferentially targeted by neurotoxins? Lancet Neurol, Vol.2, No.9, pp. 531-538

Dick, F.D. (2006). Parkinson's disease and pesticide exposures. Br Med Bull, Vol.79-80, No.1, pp. 219-231

Diguet, E., Fernagut, P.O., Wei, X., Du, Y., Rouland, R., Gross, C., Bezard, E. \& Tison, F. (2004). Deleterious effects of minocycline in animal models of Parkinson's disease and Huntington's disease. Eur J Neurosci, Vol.19, No.12, pp. 3266-3276

Dobbs, R.J., Charlett, A., Purkiss, A.G., Dobbs, S.M., Weller, C. \& Peterson, D.W. (1999). Association of circulating TNF-alpha and IL-6 with ageing and parkinsonism. Acta Neurol Scand, Vol.100, No.1, pp. 34-41

Dolle, F., Luus, C., Reynolds, A. \& Kassiou, M. (2009). Radiolabelled molecules for imaging the translocator protein $(18 \mathrm{kDa})$ using positron emission tomography. Curr Med Chem, Vol.16, No.22, pp. 2899-2923

Du, Y., Ma, Z., Lin, S., Dodel, R.C., Gao, F., Bales, K.R., Triarhou, L.C., Chernet, E., Perry, K.W., Nelson, D.L., Luecke, S., Phebus, L.A., Bymaster, F.P. \& Paul, S.M. (2001). Minocycline prevents nigrostriatal dopaminergic neurodegeneration in the MPTP model of Parkinson's disease. Proc Natl Acad Sci U S A, Vol.98, No.25, pp. 1466914674

Eder, C., Schilling, T., Heinemann, U., Haas, D., Hailer, N. \& Nitsch, R. (1999). Morphological, immunophenotypical and electrophysiological properties of resting microglia in vitro. Eur J Neurosci, Vol.11, No.12, pp. 4251-4261

Faucheux, B.A., Bonnet, A.M., Agid, Y. \& Hirsch, E.C. (1999). Blood vessels change in the mesencephalon of patients with Parkinson's disease. Lancet, Vol.353, No.9157, pp. 981-982

Ferger, B., Leng, A., Mura, A., Hengerer, B. \& Feldon, J. (2004). Genetic ablation of tumor necrosis factor-alpha (TNF-alpha) and pharmacological inhibition of TNF-synthesis attenuates MPTP toxicity in mouse striatum. J Neurochem, Vol.89, No.4, pp. 822-833 
Ferrari, C.C., Pott Godoy, M.C., Tarelli, R., Chertoff, M., Depino, A.M. \& Pitossi, F.J. (2006). Progressive neurodegeneration and motor disabilities induced by chronic expression of IL-1beta in the substantia nigra. Neurobiol Dis, Vol.24, No.1, pp. 183193

Ferrari, C.C. \& Tarelli, R. (2011). Parkinson's disease and systemic inflammation. Parkinsons Dis, Vol.2011, No., pp. 436813

Fiszer, U., Mix, E., Fredrikson, S., Kostulas, V., Olsson, T. \& Link, H. (1994). gamma delta+ T cells are increased in patients with Parkinson's disease. J Neurol Sci, Vol.121, No.1, pp. 39-45

Francis, J.W., Von Visger, J., Markelonis, G.J. \& Oh, T.H. (1995). Neuroglial responses to the dopaminergic neurotoxicant 1-methyl-4-phenyl-1,2,3,6-tetrahydropyridine in mouse striatum. Neurotoxicol Teratol, Vol.17, No.1, pp. 7-12

Gagne, J.J. \& Power, M.C. (2010). Anti-inflammatory drugs and risk of Parkinson disease: a meta-analysis. Neurology, Vol.74, No.12, pp. 995-1002

Gao, H.M. \& Hong, J.S. (2008). Why neurodegenerative diseases are progressive: uncontrolled inflammation drives disease progression. Trends Immunol, Vol.29, No.8, pp. 357-365

Gao, H.M., Liu, B., Zhang, W. \& Hong, J.S. (2003). Critical role of microglial NADPH oxidase-derived free radicals in the in vitro MPTP model of Parkinson's disease. FASEB J, Vol.17, No.13, pp. 1954-1956

Gao, X., Chen, H., Schwarzschild, M.A. \& Ascherio, A. (2011). Use of ibuprofen and risk of Parkinson disease. Neurology, Vol.76, No.10, pp. 863-869

Garden, G.A. \& Moller, T. (2006). Microglia biology in health and disease. J Neuroimmune Pharmacol, Vol.1, No.2, pp. 127-137

Gauss, K.A., Nelson-Overton, L.K., Siemsen, D.W., Gao, Y., DeLeo, F.R. \& Quinn, M.T. (2007). Role of NF-kappaB in transcriptional regulation of the phagocyte NADPH oxidase by tumor necrosis factor-alpha. J Leukoc Biol, Vol.82, No.3, pp. 729-741

Gayle, D.A., Ling, Z., Tong, C., Landers, T., Lipton, J.W. \& Carvey, P.M. (2002). Lipopolysaccharide (LPS)-induced dopamine cell loss in culture: roles of tumor necrosis factor-alpha, interleukin-1beta, and nitric oxide. Brain Res Dev Brain Res, Vol.133, No.1, pp. 27-35

Gerhard, A., Pavese, N., Hotton, G., Turkheimer, F., Es, M., Hammers, A., Eggert, K., Oertel, W., Banati, R.B. \& Brooks, D.J. (2006). In vivo imaging of microglial activation with [11C](R)-PK11195 PET in idiopathic Parkinson's disease. Neurobiol Dis, Vol.21, No.2, pp. 404-412

Ghosh, A., Roy, A., Liu, X., Kordower, J.H., Mufson, E.J., Hartley, D.M., Ghosh, S., Mosley, R.L., Gendelman, H.E. \& Pahan, K. (2007). Selective inhibition of NF-kappaB activation prevents dopaminergic neuronal loss in a mouse model of Parkinson's disease. Proc Natl Acad Sci U S A, Vol.104, No.47, pp. 18754-18759

Gibbons, H.M. \& Dragunow, M. (2006). Microglia induce neural cell death via a proximitydependent mechanism involving nitric oxide. Brain Res, Vol.1084, No.1, pp. 1-15

Graeber, M.B. \& Streit, W.J. (2010). Microglia: biology and pathology. Acta Neuropathol, Vol.119, No.1, pp. 89-105

Grilli, M., Pizzi, M., Memo, M. \& Spano, P. (1996). Neuroprotection by aspirin and sodium salicylate through blockade of NF-kappaB activation. Science, Vol.274, No.5291, pp. 1383-1385 
Hancock, D.B., Martin, E.R., Stajich, J.M., Jewett, R., Stacy, M.A., Scott, B.L., Vance, J.M. \& Scott, W.K. (2007). Smoking, caffeine, and nonsteroidal anti-inflammatory drugs in families with Parkinson disease. Arch Neurol, Vol.64, No.4, pp. 576-580

Hanisch, U.K. (2002). Microglia as a source and target of cytokines. Glia, Vol.40, No.2, pp. 140-155

He, Y., Appel, S. \& Le, W. (2001). Minocycline inhibits microglial activation and protects nigral cells after 6-hydroxydopamine injection into mouse striatum. Brain Res, Vol.909, No.1-2, pp. 187-193

Hernan, M.A., Logroscino, G. \& Garcia Rodriguez, L.A. (2006). Nonsteroidal antiinflammatory drugs and the incidence of Parkinson disease. Neurology, Vol.66, No.7, pp. 1097-1099

Herrera, A.J., Castano, A., Venero, J.L., Cano, J. \& Machado, A. (2000). The single intranigral injection of LPS as a new model for studying the selective effects of inflammatory reactions on dopaminergic system. Neurobiol Dis, Vol.7, No.4, pp. 429-447

Hirsch, E.C., Hoglinger, G., Rousselet, E., Breidert, T., Parain, K., Feger, J., Ruberg, M., Prigent, A., Cohen-Salmon, C. \& Launay, J.M. (2003). Animal models of Parkinson's disease in rodents induced by toxins: an update. J Neural Transm Suppl, Vol.65, No., pp. $89-100$

Hirsch, E.C. \& Hunot, S. (2009). Neuroinflammation in Parkinson's disease: a target for neuroprotection? Lancet Neurol, Vol.8, No.4, pp. 382-397

Hunot, S., Boissiere, F., Faucheux, B., Brugg, B., Mouatt-Prigent, A., Agid, Y. \& Hirsch, E.C. (1996). Nitric oxide synthase and neuronal vulnerability in Parkinson's disease. Neuroscience, Vol.72, No.2, pp. 355-363

Hunot, S., Brugg, B., Ricard, D., Michel, P.P., Muriel, M.P., Ruberg, M., Faucheux, B.A., Agid, Y. \& Hirsch, E.C. (1997). Nuclear translocation of NF-kappaB is increased in dopaminergic neurons of patients with parkinson disease. Proc Natl Acad Sci U S A, Vol.94, No.14, pp. 7531-7536

Hunter, R.L., Dragicevic, N., Seifert, K., Choi, D.Y., Liu, M., Kim, H.C., Cass, W.A., Sullivan, P.G. \& Bing, G. (2007). Inflammation induces mitochondrial dysfunction and dopaminergic neurodegeneration in the nigrostriatal system. J Neurochem, Vol.100, No.5, pp. 1375-1386

Imamura, K., Hishikawa, N., Sawada, M., Nagatsu, T., Yoshida, M. \& Hashizume, Y. (2003). Distribution of major histocompatibility complex class II-positive microglia and cytokine profile of Parkinson's disease brains. Acta Neuropathol, Vol.106, No.6, pp. 518-526

Jack, C.S., Arbour, N., Manusow, J., Montgrain, V., Blain, M., McCrea, E., Shapiro, A. \& Antel, J.P. (2005). TLR signaling tailors innate immune responses in human microglia and astrocytes. J Immunol, Vol.175, No.7, pp. 4320-4330

Jang, H., Boltz, D., Sturm-Ramirez, K., Shepherd, K.R., Jiao, Y., Webster, R. \& Smeyne, R.J. (2009b). Highly pathogenic H5N1 influenza virus can enter the central nervous system and induce neuroinflammation and neurodegeneration. Proc Natl Acad Sci U S A, Vol.106, No.33, pp. 14063-14068

Jang, H., Boltz, D.A., Webster, R.G. \& Smeyne, R.J. (2009a). Viral parkinsonism. Biochim Biophys Acta, Vol.1792, No.7, pp. 714-721

Jenner, P. (2003). Oxidative stress in Parkinson's disease. Ann Neurol, Vol.53 Suppl 3, No., pp. S26-36; discussion S36-28 
Johnston, L.C., Su, X., Maguire-Zeiss, K., Horovitz, K., Ankoudinova, I., Guschin, D., Hadaczek, P., Federoff, H.J., Bankiewicz, K. \& Forsayeth, J. (2008). Human interleukin-10 gene transfer is protective in a rat model of Parkinson's disease. Mol Ther, Vol.16, No.8, pp. 1392-1399

Kettenmann, H., Banati, R. \& Walz, W. (1993). Electrophysiological behavior of microglia. Glia, Vol.7, No.1, pp. 93-101

Kim, H.J., Hawke, N. \& Baldwin, A.S. (2006). NF-kappaB and IKK as therapeutic targets in cancer. Cell Death Differ, Vol.13, No.5, pp. 738-747

Kim, H.S. \& Suh, Y.H. (2009). Minocycline and neurodegenerative diseases. Behav Brain Res, Vol.196, No.2, pp. 168-179

Kim, S.U. \& de Vellis, J. (2005). Microglia in health and disease. J Neurosci Res, Vol.81, No.3, pp. 302-313

Kim, W.G., Mohney, R.P., Wilson, B., Jeohn, G.H., Liu, B. \& Hong, J.S. (2000). Regional difference in susceptibility to lipopolysaccharide-induced neurotoxicity in the rat brain: role of microglia. J Neurosci, Vol.20, No.16, pp. 6309-6316

Kim, Y.S., Choi, D.H., Block, M.L., Lorenzl, S., Yang, L., Kim, Y.J., Sugama, S., Cho, B.P., Hwang, O., Browne, S.E., Kim, S.Y., Hong, J.S., Beal, M.F. \& Joh, T.H. (2007). A pivotal role of matrix metalloproteinase-3 activity in dopaminergic neuronal degeneration via microglial activation. FASEB J, Vol.21, No.1, pp. 179-187

Kim, Y.S., Kim, S.S., Cho, J.J., Choi, D.H., Hwang, O., Shin, D.H., Chun, H.S., Beal, M.F. \& Joh, T.H. (2005). Matrix metalloproteinase-3: a novel signaling proteinase from apoptotic neuronal cells that activates microglia. J Neurosci, Vol.25, No.14, pp. 37013711

Kirik, D., Rosenblad, C. \& Bjorklund, A. (1998). Characterization of behavioral and neurodegenerative changes following partial lesions of the nigrostriatal dopamine system induced by intrastriatal 6-hydroxydopamine in the rat. Exp Neurol, Vol.152, No.2, pp. 259-277

Knott, C., Stern, G. \& Wilkin, G.P. (2000). Inflammatory regulators in Parkinson's disease: iNOS, lipocortin-1, and cyclooxygenases-1 and -2. Mol Cell Neurosci, Vol.16, No.6, pp. 724-739

Kohutnicka, M., Lewandowska, E., Kurkowska-Jastrzebska, I., Czlonkowski, A. \& Czlonkowska, A. (1998). Microglial and astrocytic involvement in a murine model of Parkinson's disease induced by 1-methyl-4-phenyl-1,2,3,6-tetrahydropyridine (MPTP). Immunopharmacology, Vol.39, No.3, pp. 167-180

Konsman, J.P., Parnet, P. \& Dantzer, R. (2002). Cytokine-induced sickness behaviour: mechanisms and implications. Trends Neurosci, Vol.25, No.3, pp. 154-159

Kopp, E. \& Ghosh, S. (1994). Inhibition of NF-kappa B by sodium salicylate and aspirin. Science, Vol.265, No.5174, pp. 956-959

Koprich, J.B., Reske-Nielsen, C., Mithal, P. \& Isacson, O. (2008). Neuroinflammation mediated by IL-1beta increases susceptibility of dopamine neurons to degeneration in an animal model of Parkinson's disease. J Neuroinflammation, Vol.5, No., pp. 8

Kortekaas, R., Leenders, K.L., van Oostrom, J.C., Vaalburg, W., Bart, J., Willemsen, A.T. \& Hendrikse, N.H. (2005). Blood-brain barrier dysfunction in parkinsonian midbrain in vivo. Ann Neurol, Vol.57, No.2, pp. 176-179 
Kurkowska-Jastrzebska, I., Babiuch, M., Joniec, I., Przybylkowski, A., Czlonkowski, A. \& Czlonkowska, A. (2002). Indomethacin protects against neurodegeneration caused by MPTP intoxication in mice. Int Immunopharmacol, Vol.2, No.8, pp. 1213-1218

Kurkowska-Jastrzebska, I., Litwin, T., Joniec, I., Ciesielska, A., Przybylkowski, A., Czlonkowski, A. \& Czlonkowska, A. (2004). Dexamethasone protects against dopaminergic neurons damage in a mouse model of Parkinson's disease. Int Immunopharmacol, Vol.4, No.10-11, pp. 1307-1318

Ladeby, R., Wirenfeldt, M., Garcia-Ovejero, D., Fenger, C., Dissing-Olesen, L., Dalmau, I. \& Finsen, B. (2005). Microglial cell population dynamics in the injured adult central nervous system. Brain Res Brain Res Rev, Vol.48, No.2, pp. 196-206

Langston, J.W., Ballard, P., Tetrud, J.W. \& Irwin, I. (1983). Chronic Parkinsonism in humans due to a product of meperidine-analog synthesis. Science, Vol.219, No.4587, pp. 979980

Langston, J.W. \& Ballard, P.A., Jr. (1983). Parkinson's disease in a chemist working with 1methyl-4-phenyl-1,2,5,6-tetrahydropyridine. N Engl J Med, Vol.309, No.5, pp. 310

Langston, J.W., Forno, L.S., Tetrud, J., Reeves, A.G., Kaplan, J.A. \& Karluk, D. (1999). Evidence of active nerve cell degeneration in the substantia nigra of humans years after 1-methyl-4-phenyl-1,2,3,6-tetrahydropyridine exposure. Ann Neurol, Vol.46, No.4, pp. 598-605

Leng, A., Mura, A., Feldon, J. \& Ferger, B. (2005). Tumor necrosis factor-alpha receptor ablation in a chronic MPTP mouse model of Parkinson's disease. Neurosci Lett, Vol.375, No.2, pp. 107-111

Liberatore, G.T., Jackson-Lewis, V., Vukosavic, S., Mandir, A.S., Vila, M., McAuliffe, W.G., Dawson, V.L., Dawson, T.M. \& Przedborski, S. (1999). Inducible nitric oxide synthase stimulates dopaminergic neurodegeneration in the MPTP model of Parkinson disease. Nat Med, Vol.5, No.12, pp. 1403-1409

Ling, Z., Gayle, D.A., Ma, S.Y., Lipton, J.W., Tong, C.W., Hong, J.S. \& Carvey, P.M. (2002). In utero bacterial endotoxin exposure causes loss of tyrosine hydroxylase neurons in the postnatal rat midbrain. Mov Disord, Vol.17, No.1, pp. 116-124

Ling, Z., Zhu, Y., Tong, C., Snyder, J.A., Lipton, J.W. \& Carvey, P.M. (2006). Progressive dopamine neuron loss following supra-nigral lipopolysaccharide (LPS) infusion into rats exposed to LPS prenatally. Exp Neurol, Vol.199, No.2, pp. 499-512

Ling, Z.D., Chang, Q., Lipton, J.W., Tong, C.W., Landers, T.M. \& Carvey, P.M. (2004). Combined toxicity of prenatal bacterial endotoxin exposure and postnatal 6hydroxydopamine in the adult rat midbrain. Neuroscience, Vol.124, No.3, pp. 619628

Long-Smith, C.M., Collins, L., Toulouse, A., Sullivan, A.M. \& Nolan, Y.M. (2010). Interleukin-1beta contributes to dopaminergic neuronal death induced by lipopolysaccharide-stimulated rat glia in vitro. J Neuroimmunol, Vol.226, No.1-2, pp. 20-26

Long-Smith, C.M., Sullivan, A.M. \& Nolan, Y.M. (2009). The influence of microglia on the pathogenesis of Parkinson's disease. Prog Neurobiol, Vol.89, No.3, pp. 277-287

Lyons, A., Downer, E.J., Crotty, S., Nolan, Y.M., Mills, K.H. \& Lynch, M.A. (2007). CD200 ligand receptor interaction modulates microglial activation in vivo and in vitro: a role for IL-4. J Neurosci, Vol.27, No.31, pp. 8309-8313 
McCoy, M.K., Martinez, T.N., Ruhn, K.A., Szymkowski, D.E., Smith, C.G., Botterman, B.R., Tansey, K.E. \& Tansey, M.G. (2006). Blocking soluble tumor necrosis factor signaling with dominant-negative tumor necrosis factor inhibitor attenuates loss of dopaminergic neurons in models of Parkinson's disease. J Neurosci, Vol.26, No.37, pp. $9365-9375$

McCoy, M.K., Ruhn, K.A., Martinez, T.N., McAlpine, F.E., Blesch, A. \& Tansey, M.G. (2008). Intranigral lentiviral delivery of dominant-negative TNF attenuates neurodegeneration and behavioral deficits in hemiparkinsonian rats. Mol Ther, Vol.16, No.9, pp. 1572-1579

McGeer, E.G. \& McGeer, P.L. (2007). The role of anti-inflammatory agents in Parkinson's disease. CNS Drugs, Vol.21, No.10, pp. 789-797

McGeer, P.L., Itagaki, S., Boyes, B.E. \& McGeer, E.G. (1988). Reactive microglia are positive for HLA-DR in the substantia nigra of Parkinson's and Alzheimer's disease brains. Neurology, Vol.38, No.8, pp. 1285-1291

McGeer, P.L. \& McGeer, E.G. (2004). Inflammation and the degenerative diseases of aging. Ann N Y Acad Sci, Vol.1035, No., pp. 104-116

McGeer, P.L., Schwab, C., Parent, A. \& Doudet, D. (2003). Presence of reactive microglia in monkey substantia nigra years after 1-methyl-4-phenyl-1,2,3,6-tetrahydropyridine administration. Ann Neurol, Vol.54, No.5, pp. 599-604

McGettrick, A.F. \& O'Neill, L.A. (2010). Regulators of TLR4 signaling by endotoxins. Subcell Biochem, Vol.53, No.1, pp. 153-171

Misra, U.K. \& Kalita, J. (2010). Overview: Japanese encephalitis. Prog Neurobiol, Vol.91, No.2, pp. $108-120$

Mitchell, J.A., Akarasereenont, P., Thiemermann, C., Flower, R.J. \& Vane, J.R. (1993). Selectivity of nonsteroidal antiinflammatory drugs as inhibitors of constitutive and inducible cyclooxygenase. Proc Natl Acad Sci U S A, Vol.90, No.24, pp. 11693-11697

Mogi, M., Harada, M., Kondo, T., Riederer, P., Inagaki, H., Minami, M. \& Nagatsu, T. (1994a). Interleukin-1 beta, interleukin-6, epidermal growth factor and transforming growth factor-alpha are elevated in the brain from parkinsonian patients. Neurosci Lett, Vol.180, No.2, pp. 147-150

Mogi, M., Harada, M., Riederer, P., Narabayashi, H., Fujita, K. \& Nagatsu, T. (1994b). Tumor necrosis factor-alpha (TNF-alpha) increases both in the brain and in the cerebrospinal fluid from parkinsonian patients. Neurosci Lett, Vol.165, No.1-2, pp. 208-210

Mogi, M., Togari, A., Kondo, T., Mizuno, Y., Komure, O., Kuno, S., Ichinose, H. \& Nagatsu, T. (2000). Caspase activities and tumor necrosis factor receptor R1 (p55) level are elevated in the substantia nigra from parkinsonian brain. J Neural Transm, Vol.107, No.3, pp. 335-341

Nadeau, S. \& Rivest, S. (2003). Glucocorticoids play a fundamental role in protecting the brain during innate immune response. J Neurosci, Vol.23, No.13, pp. 5536-5544

Nakajima, K. \& Kohsaka, S. (2001). Microglia: activation and their significance in the central nervous system. J Biochem, Vol.130, No.2, pp. 169-175

Nakamura, Y. (2002). Regulating factors for microglial activation. Biol Pharm Bull, Vol.25, No.8, pp. $945-953$ 
Nimmerjahn, A., Kirchhoff, F. \& Helmchen, F. (2005). Resting microglial cells are highly dynamic surveillants of brain parenchyma in vivo. Science, Vol.308, No.5726, pp. 1314-1318

NINDS-NET-PD-Investigators. (2006). A randomized, double-blind, futility clinical trial of creatine and minocycline in early Parkinson disease. Neurology, Vol.66, No.5, pp. 664-671

NINDS-NET-PD-Investigators. (2008). A pilot clinical trial of creatine and minocycline in early Parkinson disease: 18-month results. Clin Neuropharmacol, Vol.31, No.3, pp. 141-150

Nolan, Y., Maher, F.O., Martin, D.S., Clarke, R.M., Brady, M.T., Bolton, A.E., Mills, K.H. \& Lynch, M.A. (2005). Role of interleukin-4 in regulation of age-related inflammatory changes in the hippocampus. J Biol Chem, Vol.280, No.10, pp. 9354-9362

O'Callaghan, J.P., Miller, D.B. \& Reinhard, J.F., Jr. (1990). Characterization of the origins of astrocyte response to injury using the dopaminergic neurotoxicant, 1-methyl-4phenyl-1,2,3,6-tetrahydropyridine. Brain Res, Vol.521, No.1-2, pp. 73-80

Ogata, A., Tashiro, K., Nukuzuma, S., Nagashima, K. \& Hall, W.W. (1997). A rat model of Parkinson's disease induced by Japanese encephalitis virus. J Neurovirol, Vol.3, No.2, pp. 141-147

Ogata, A., Tashiro, K. \& Pradhan, S. (2000). Parkinsonism due to predominant involvement of substantia nigra in Japanese encephalitis. Neurology, Vol.55, No.4, pp. 602

Orr, C.F., Rowe, D.B. \& Halliday, G.M. (2002). An inflammatory review of Parkinson's disease. Prog Neurobiol, Vol.68, No.5, pp. 325-340

Ouchi, Y., Yagi, S., Yokokura, M. \& Sakamoto, M. (2009). Neuroinflammation in the living brain of Parkinson's disease. Parkinsonism Relat Disord, Vol.15 Suppl 3, No., pp. S200-204

Pankratz, N. \& Foroud, T. (2007). Genetics of Parkinson disease. Genet Med, Vol.9, No.12, pp. 801-811

Papadopoulos, V., Baraldi, M., Guilarte, T.R., Knudsen, T.B., Lacapere, J.J., Lindemann, P., Norenberg, M.D., Nutt, D., Weizman, A., Zhang, M.R. \& Gavish, M. (2006). Translocator protein $(18 \mathrm{kDa})$ : new nomenclature for the peripheral-type benzodiazepine receptor based on its structure and molecular function. Trends Pharmacol Sci, Vol.27, No.8, pp. 402-409

Park, C.H., Carboni, E., Wood, P.L. \& Gee, K.W. (1996). Characterization of peripheral benzodiazepine type sites in a cultured murine BV-2 microglial cell line. Glia, Vol.16, No.1, pp. 65-70

Perry, V.H. (1998). A revised view of the central nervous system microenvironment and major histocompatibility complex class II antigen presentation. J Neuroimmunol, Vol.90, No.2, pp. 113-121

Perry, V.H. (2010). Contribution of systemic inflammation to chronic neurodegeneration. Acta Neuropathol, Vol.120, No.3, pp. 277-286

Perry, V.H., Cunningham, C. \& Holmes, C. (2007). Systemic infections and inflammation affect chronic neurodegeneration. Nat Rev Immunol, Vol.7, No.2, pp. 161-167

Poser, C.M., Huntley, C.J. \& Poland, J.D. (1969). Para-encephalitic parkinsonism. Report of an acute case due to coxsackie virus type B 2 and re-examination of the etiologic concepts of postencephalitic parkinsonism. Acta Neurol Scand, Vol.45, No.2, pp. 199215 
Pott Godoy, M.C., Tarelli, R., Ferrari, C.C., Sarchi, M.I. \& Pitossi, F.J. (2008). Central and systemic IL-1 exacerbates neurodegeneration and motor symptoms in a model of Parkinson's disease. Brain, Vol.131, No.Pt 7, pp. 1880-1894

Pranzatelli, M.R., Mott, S.H., Pavlakis, S.G., Conry, J.A. \& Tate, E.D. (1994). Clinical spectrum of secondary parkinsonism in childhood: a reversible disorder. Pediatr Neurol, Vol.10, No.2, pp. 131-140

Przedborski, S. \& Vila, M. (2003). The 1-methyl-4-phenyl-1,2,3,6-tetrahydropyridine mouse model: a tool to explore the pathogenesis of Parkinson's disease. Ann N Y Acad Sci, Vol.991, No., pp. 189-198

Qian, L., Hong, J.S. \& Flood, P.M. (2006). Role of microglia in inflammation-mediated degeneration of dopaminergic neurons: neuroprotective effect of interleukin 10. J Neural Transm Suppl, Vol., No.70, pp. 367-371

Qin, L., Wu, X., Block, M.L., Liu, Y., Breese, G.R., Hong, J.S., Knapp, D.J. \& Crews, F.T. (2007). Systemic LPS causes chronic neuroinflammation and progressive neurodegeneration. Glia, Vol.55, No.5, pp. 453-462

Quinn, L.P., Crook, B., Hows, M.E., Vidgeon-Hart, M., Chapman, H., Upton, N., Medhurst, A.D. \& Virley, D.J. (2008). The PPARgamma agonist pioglitazone is effective in the MPTP mouse model of Parkinson's disease through inhibition of monoamine oxidase B. Br J Pharmacol, Vol.154, No.1, pp. 226-233

Rail, D., Scholtz, C. \& Swash, M. (1981). Post-encephalitic Parkinsonism: current experience. J Neurol Neurosurg Psychiatry, Vol.44, No.8, pp. 670-676

Raivich, G., Bohatschek, M., Kloss, C.U., Werner, A., Jones, L.L. \& Kreutzberg, G.W. (1999). Neuroglial activation repertoire in the injured brain: graded response, molecular mechanisms and cues to physiological function. Brain Res Brain Res Rev, Vol.30, No.1, pp. 77-105

Ransohoff, R.M. \& Cardona, A.E. (2010). The myeloid cells of the central nervous system parenchyma. Nature, Vol.468, No.7321, pp. 253-262

Ransohoff, R.M. \& Perry, V.H. (2009). Microglial physiology: unique stimuli, specialized responses. Annu Rev Immunol, Vol.27, No., pp. 119-145

Reale, M., Iarlori, C., Thomas, A., Gambi, D., Perfetti, B., Di Nicola, M. \& Onofrj, M. (2009). Peripheral cytokines profile in Parkinson's disease. Brain Behav Immun, Vol.23, No.1, pp. 55-63

Rentzos, M., Nikolaou, C., Andreadou, E., Paraskevas, G.P., Rombos, A., Zoga, M., Tsoutsou, A., Boufidou, F., Kapaki, E. \& Vassilopoulos, D. (2007). Circulating interleukin-15 and RANTES chemokine in Parkinson's disease. Acta Neurol Scand, Vol.116, No.6, pp. 374-379

Robinson, R.L., Shahida, S., Madan, N., Rao, S. \& Khardori, N. (2003). Transient parkinsonism in West Nile virus encephalitis. Am J Med, Vol.115, No.3, pp. 252-253

Samii, A., Etminan, M., Wiens, M.O. \& Jafari, S. (2009). NSAID use and the risk of Parkinson's disease: systematic review and meta-analysis of observational studies. Drugs Aging, Vol.26, No.9, pp. 769-779

Sampaio, E.P., Sarno, E.N., Galilly, R., Cohn, Z.A. \& Kaplan, G. (1991). Thalidomide selectively inhibits tumor necrosis factor alpha production by stimulated human monocytes. J Exp Med, Vol.173, No.3, pp. 699-703 
Sanchez-Pernaute, R., Ferree, A., Cooper, O., Yu, M., Brownell, A.L. \& Isacson, O. (2004). Selective COX-2 inhibition prevents progressive dopamine neuron degeneration in a rat model of Parkinson's disease. J Neuroinflammation, Vol.1, No.1, pp. 6

Santambrogio, L., Belyanskaya, S.L., Fischer, F.R., Cipriani, B., Brosnan, C.F., RicciardiCastagnoli, P., Stern, L.J., Strominger, J.L. \& Riese, R. (2001). Developmental plasticity of CNS microglia. Proc Natl Acad Sci U S A, Vol.98, No.11, pp. 6295-6300

Sauer, H. \& Oertel, W.H. (1994). Progressive degeneration of nigrostriatal dopamine neurons following intrastriatal terminal lesions with 6-hydroxydopamine: a combined retrograde tracing and immunocytochemical study in the rat. Neuroscience, Vol.59, No.2, pp. 401-415

Sawada, M., Imamura, K. \& Nagatsu, T. (2006). Role of cytokines in inflammatory process in Parkinson's disease. J Neural Transm Suppl, Vol., No.70, pp. 373-381

Scheinman, R.I., Gualberto, A., Jewell, C.M., Cidlowski, J.A. \& Baldwin, A.S., Jr. (1995). Characterization of mechanisms involved in transrepression of NF-kappa B by activated glucocorticoid receptors. Mol Cell Biol, Vol.15, No.2, pp. 943-953

Schintu, N., Frau, L., Ibba, M., Caboni, P., Garau, A., Carboni, E. \& Carta, A.R. (2009). PPARgamma-mediated neuroprotection in a chronic mouse model of Parkinson's disease. Eur J Neurosci, Vol.29, No.5, pp. 954-963

Sedgwick, J.D., Schwender, S., Imrich, H., Dorries, R., Butcher, G.W. \& ter Meulen, V. (1991). Isolation and direct characterization of resident microglial cells from the normal and inflamed central nervous system. Proc Natl Acad Sci U S A, Vol.88, No.16, pp. 7438-7442

Shan, S., Hong-Min, T., Yi, F., Jun-Peng, G., Yue, F., Yan-Hong, T., Yun-Ke, Y., Wen-Wei, L., Xiang-Yu, W., Jun, M., Guo-Hua, W., Ya-Ling, H., Hua-Wei, L. \& Ding-Fang, C. (2011). NEW evidences for fractalkine/CX3CL1 involved in substantia nigral microglial activation and behavioral changes in a rat model of Parkinson's disease. Neurobiol Aging, Vol.32, No.3, pp. 443-458

Shoji, H., Watanabe, M., Itoh, S., Kuwahara, H. \& Hattori, F. (1993). Japanese encephalitis and parkinsonism. J Neurol, Vol.240, No.1, pp. 59-60

Sian, J., Dexter, D.T., Lees, A.J., Daniel, S., Agid, Y., Javoy-Agid, F., Jenner, P. \& Marsden, C.D. (1994). Alterations in glutathione levels in Parkinson's disease and other neurodegenerative disorders affecting basal ganglia. Ann Neurol, Vol.36, No.3, pp. 348-355

Smithells, R.W. \& Newman, C.G. (1992). Recognition of thalidomide defects. J Med Genet, Vol.29, No.10, pp. 716-723

Sriram, K., Matheson, J.M., Benkovic, S.A., Miller, D.B., Luster, M.I. \& O'Callaghan, J.P. (2006). Deficiency of TNF receptors suppresses microglial activation and alters the susceptibility of brain regions to MPTP-induced neurotoxicity: role of TNF-alpha. FASEB J, Vol.20, No.6, pp. 670-682

Stanic, D., Finkelstein, D.I., Bourke, D.W., Drago, J. \& Horne, M.K. (2003). Timecourse of striatal re-innervation following lesions of dopaminergic SNpc neurons of the rat. Eur J Neurosci, Vol.18, No.5, pp. 1175-1188

Stephenson, D.T., Schober, D.A., Smalstig, E.B., Mincy, R.E., Gehlert, D.R. \& Clemens, J.A. (1995). Peripheral benzodiazepine receptors are colocalized with activated microglia following transient global forebrain ischemia in the rat. J Neurosci, Vol.15, No.7 Pt 2, pp. 5263-5274 
Stone, D.K., Reynolds, A.D., Mosley, R.L. \& Gendelman, H.E. (2009). Innate and adaptive immunity for the pathobiology of Parkinson's disease. Antioxid Redox Signal, Vol.11, No.9, pp. 2151-2166

Stypula, G., Kunert-Radek, J., Stepien, H., Zylinska, K. \& Pawlikowski, M. (1996). Evaluation of interleukins, ACTH, cortisol and prolactin concentrations in the blood of patients with parkinson's disease. Neuroimmunomodulation, Vol.3, No.2-3, pp. 131-134

Takahashi, M., Yamada, T., Nakajima, S., Nakajima, K., Yamamoto, T. \& Okada, H. (1995). The substantia nigra is a major target for neurovirulent influenza A virus. J Exp Med, Vol.181, No.6, pp. 2161-2169

Tansey, M.G. \& Goldberg, M.S. (2010). Neuroinflammation in Parkinson's disease: its role in neuronal death and implications for therapeutic intervention. Neurobiol Dis, Vol.37, No.3, pp. 510-518

Tansey, M.G., McCoy, M.K. \& Frank-Cannon, T.C. (2007). Neuroinflammatory mechanisms in Parkinson's disease: potential environmental triggers, pathways, and targets for early therapeutic intervention. Exp Neurol, Vol.208, No.1, pp. 1-25

Teismann, P. \& Ferger, B. (2001). Inhibition of the cyclooxygenase isoenzymes COX-1 and COX-2 provide neuroprotection in the MPTP-mouse model of Parkinson's disease. Synapse, Vol.39, No.2, pp. 167-174

Teismann, P., Tieu, K., Choi, D.K., Wu, D.C., Naini, A., Hunot, S., Vila, M., Jackson-Lewis, V. \& Przedborski, S. (2003). Cyclooxygenase-2 is instrumental in Parkinson's disease neurodegeneration. Proc Natl Acad Sci U S A, Vol.100, No.9, pp. 5473-5478

Teo, B.H. \& Wong, S.H. (2010). MHC class II-associated invariant chain (Ii) modulates dendritic cells-derived microvesicles (DCMV)-mediated activation of microglia. Biochem Biophys Res Commun, Vol.400, No.4, pp. 673-678

Tomas-Camardiel, M., Rite, I., Herrera, A.J., de Pablos, R.M., Cano, J., Machado, A. \& Venero, J.L. (2004). Minocycline reduces the lipopolysaccharide-induced inflammatory reaction, peroxynitrite-mediated nitration of proteins, disruption of the blood-brain barrier, and damage in the nigral dopaminergic system. Neurobiol Dis, Vol.16, No.1, pp. 190-201

Tomiyama, H., Mizuta, I., Li, Y., Funayama, M., Yoshino, H., Li, L., Murata, M., Yamamoto, M., Kubo, S., Mizuno, Y., Toda, T. \& Hattori, N. (2008). LRRK2 P755L variant in sporadic Parkinson's disease. J Hum Genet, Vol.53, No.11-12, pp. 1012-1015

Toulouse, A. \& Sullivan, A.M. (2008). Progress in Parkinson's disease-where do we stand? Prog Neurobiol, Vol.85, No.4, pp. 376-392

Tse, W., Cersosimo, M.G., Gracies, J.M., Morgello, S., Olanow, C.W. \& Koller, W. (2004). Movement disorders and AIDS: a review. Parkinsonism Relat Disord, Vol.10, No.6, pp. 323-334

Tweedie, D., Sambamurti, K. \& Greig, N.H. (2007). TNF-alpha inhibition as a treatment strategy for neurodegenerative disorders: new drug candidates and targets. Curr Alzheimer Res, Vol.4, No.4, pp. 378-385

Walters, J.H. (1960). Postencephalitic Parkinson syndrome after meningoencephalitis due to coxsackie virus group B, type 2. New England Journal of Medicine, Vol.263, No.15, pp. 744-747

Wang, S., Yan, J.Y., Lo, Y.K., Carvey, P.M. \& Ling, Z. (2009). Dopaminergic and serotoninergic deficiencies in young adult rats prenatally exposed to the bacterial lipopolysaccharide. Brain Res, Vol.1265, No., pp. 196-204 
Wang, X.J., Zhang, S., Yan, Z.Q., Zhao, Y.X., Zhou, H.Y., Wang, Y., Lu, G.Q. \& Zhang, J.D. (2011). Impaired CD200-CD200R-mediated microglia silencing enhances midbrain dopaminergic neurodegeneration: Roles of aging, superoxide, NADPH oxidase, and p38 MAPK. Free Radic Biol Med, Vol.50, No.9, pp. 1094-1106

Weller, C., Oxlade, N., Dobbs, S.M., Dobbs, R.J., Charlett, A. \& Bjarnason, I.T. (2005). Role of inflammation in gastrointestinal tract in aetiology and pathogenesis of idiopathic parkinsonism. FEMS Immunol Med Microbiol, Vol.44, No.2, pp. 129-135

Wilms, H., Rosenstiel, P., Sievers, J., Deuschl, G., Zecca, L. \& Lucius, R. (2003). Activation of microglia by human neuromelanin is NF-kappaB dependent and involves p38 mitogen-activated protein kinase: implications for Parkinson's disease. FASEB J, Vol.17, No.3, pp. 500-502

Wilms, H., Zecca, L., Rosenstiel, P., Sievers, J., Deuschl, G. \& Lucius, R. (2007). Inflammation in Parkinson's diseases and other neurodegenerative diseases: cause and therapeutic implications. Curr Pharm Des, Vol.13, No.18, pp. 1925-1928

Winkeler, A., Boisgard, R., Martin, A. \& Tavitian, B. (2010). Radioisotopic imaging of neuroinflammation. J Nucl Med, Vol.51, No.1, pp. 1-4

Wu, D.C., Jackson-Lewis, V., Vila, M., Tieu, K., Teismann, P., Vadseth, C., Choi, D.K., Ischiropoulos, H. \& Przedborski, S. (2002). Blockade of microglial activation is neuroprotective in the 1-methyl-4-phenyl-1,2,3,6-tetrahydropyridine mouse model of Parkinson disease. J Neurosci, Vol.22, No.5, pp. 1763-1771

Wu, D.C., Teismann, P., Tieu, K., Vila, M., Jackson-Lewis, V., Ischiropoulos, H. \& Przedborski, S. (2003). NADPH oxidase mediates oxidative stress in the 1-methyl-4phenyl-1,2,3,6-tetrahydropyridine model of Parkinson's disease. Proc Natl Acad Sci U S A, Vol.100, No.10, pp. 6145-6150

Yamada, T., McGeer, P.L. \& McGeer, E.G. (1992). Lewy bodies in Parkinson's disease are recognized by antibodies to complement proteins. Acta Neuropathol, Vol.84, No.1, pp. 100-104

Yang, L., Sugama, S., Chirichigno, J.W., Gregorio, J., Lorenzl, S., Shin, D.H., Browne, S.E., Shimizu, Y., Joh, T.H., Beal, M.F. \& Albers, D.S. (2003). Minocycline enhances MPTP toxicity to dopaminergic neurons. J Neurosci Res, Vol.74, No.2, pp. 278-285

Yasuda, T., Fukuda-Tani, M., Nihira, T., Wada, K., Hattori, N., Mizuno, Y. \& Mochizuki, H. (2007). Correlation between levels of pigment epithelium-derived factor and vascular endothelial growth factor in the striatum of patients with Parkinson's disease. Exp Neurol, Vol.206, No.2, pp. 308-317

Yirmiya, R., Winocur, G. \& Goshen, I. (2002). Brain interleukin-1 is involved in spatial memory and passive avoidance conditioning. Neurobiol Learn Mem, Vol.78, No.2, pp. 379-389

Zalcman, S., Green-Johnson, J.M., Murray, L., Nance, D.M., Dyck, D., Anisman, H. \& Greenberg, A.H. (1994). Cytokine-specific central monoamine alterations induced by interleukin-1, -2 and -6. Brain Res, Vol.643, No.1-2, pp. 40-49

Zhang, F., Qian, L., Flood, P.M., Shi, J.S., Hong, J.S. \& Gao, H.M. (2010). Inhibition of IkappaB kinase-beta protects dopamine neurons against lipopolysaccharideinduced neurotoxicity. J Pharmacol Exp Ther, Vol.333, No.3, pp. 822-833

Zhang, W., Wang, T., Pei, Z., Miller, D.S., Wu, X., Block, M.L., Wilson, B., Zhou, Y., Hong, J.S. \& Zhang, J. (2005). Aggregated alpha-synuclein activates microglia: a process 
leading to disease progression in Parkinson's disease. FASEB J, Vol.19, No.6, pp. 533-542

Zhou, Y., Su, Y., Li, B., Liu, F., Ryder, J.W., Wu, X., Gonzalez-DeWhitt, P.A., Gelfanova, V., Hale, J.E., May, P.C., Paul, S.M. \& Ni, B. (2003). Nonsteroidal anti-inflammatory drugs can lower amyloidogenic Abeta42 by inhibiting Rho. Science, Vol.302, No.5648, pp. 1215-1217 


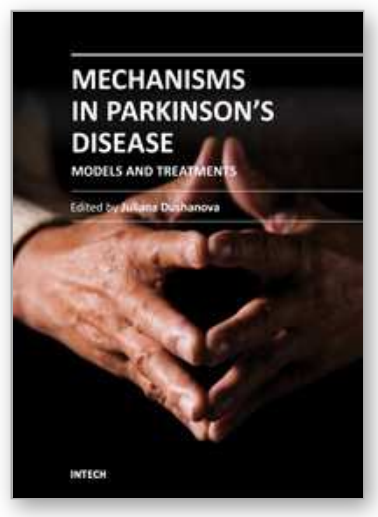

\author{
Mechanisms in Parkinson's Disease - Models and Treatments \\ Edited by Dr. Juliana Dushanova
}

ISBN 978-953-307-876-2

Hard cover, 582 pages

Publisher InTech

Published online 08, February, 2012

Published in print edition February, 2012

Parkinson's disease (PD) results primarily from the death of dopaminergic neurons in the substantia nigra. Current PD medications treat symptoms; none halt or retard dopaminergic neuron degeneration. The main obstacle to developing neuroprotective therapies is a limited understanding of the key molecular mechanisms that provoke neurodegeneration. The discovery of PD genes has led to the hypothesis that misfolding of proteins and dysfunction of the ubiquitin-proteasome pathway are pivotal to PD pathogenesis. Previously implicated culprits in PD neurodegeneration, mitochondrial dysfunction, and oxidative stress may also act in part by causing the accumulation of misfolded proteins, in addition to producing other deleterious events in dopaminergic neurons. Neurotoxin-based models have been important in elucidating the molecular cascade of cell death in dopaminergic neurons. PD models based on the manipulation of PD genes should prove valuable in elucidating important aspects of the disease, such as selective vulnerability of substantia nigra dopaminergic neurons to the degenerative process.

\title{
How to reference
}

In order to correctly reference this scholarly work, feel free to copy and paste the following:

Louise M. Collins, André Toulouse and Yvonne M. Nolan (2012). Inflammation in Parkinson's Disease: Causes and Consequences, Mechanisms in Parkinson's Disease - Models and Treatments, Dr. Juliana Dushanova (Ed.), ISBN: 978-953-307-876-2, InTech, Available from: http://www.intechopen.com/books/mechanisms-inparkinson-s-disease-models-and-treatments/inflammation-in-parkinson-s-disease-causes-and-consequences

\section{INTECH}

open science | open minds

\section{InTech Europe}

University Campus STeP Ri

Slavka Krautzeka 83/A

51000 Rijeka, Croatia

Phone: +385 (51) 770447

Fax: +385 (51) 686166

www.intechopen.com

\section{InTech China}

Unit 405, Office Block, Hotel Equatorial Shanghai

No.65, Yan An Road (West), Shanghai, 200040, China

中国上海市延安西路65号上海国际贵都大饭店办公楼 405 单元

Phone: +86-21-62489820

Fax: $+86-21-62489821$ 
(C) 2012 The Author(s). Licensee IntechOpen. This is an open access article distributed under the terms of the Creative Commons Attribution 3.0 License, which permits unrestricted use, distribution, and reproduction in any medium, provided the original work is properly cited. 